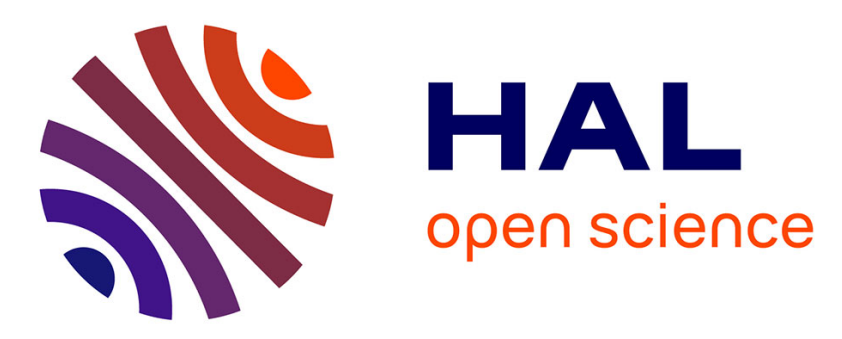

\title{
Review of Electrochemically Triggered Macromolecular Film Buildup Processes and Their Biomedical Applications
}

Clément Maerten, Loïc Jierry, Pierre Schaaf, Fouzia Boulmedais

\section{- To cite this version:}

Clément Maerten, Loïc Jierry, Pierre Schaaf, Fouzia Boulmedais. Review of Electrochemically Triggered Macromolecular Film Buildup Processes and Their Biomedical Applications. ACS Applied Materials \& Interfaces, 2017, 9 (34), pp.28117-28138. 10.1021/acsami.7b06319 . hal-02481281

\section{HAL Id: hal-02481281 \\ https://hal.science/hal-02481281}

Submitted on 17 Feb 2020

HAL is a multi-disciplinary open access archive for the deposit and dissemination of scientific research documents, whether they are published or not. The documents may come from teaching and research institutions in France or abroad, or from public or private research centers.
L'archive ouverte pluridisciplinaire HAL, est destinée au dépôt et à la diffusion de documents scientifiques de niveau recherche, publiés ou non, émanant des établissements d'enseignement et de recherche français ou étrangers, des laboratoires publics ou privés. 


\section{Review of electrochemically triggered}

\section{macromolecular film buildup processes and their}

\section{biomedical applications}

Clément Maerten, ${ }^{1}$ Loïc Jierry, ${ }^{1}$ Pierre Schaaf ${ }^{1,2,3,4}$ and Fouzia Boulmedais ${ }^{*}, 1,4$

1. Université de Strasbourg, CNRS, Institut Charles Sadron UPR 22, 23 rue du Loess, F-67034

Strasbourg Cedex, France.

2. INSERM, Unité 1121 "Biomaterials and Bioengineering", 11 rue Humann, F-67085

Strasbourg Cedex, France.

3. Université de Strasbourg, Faculté de Chirurgie Dentaire, Fédération de Médecine

Translationnelle de Strasbourg (FMTS), and Fédération des Matériaux et Nanoscience d'Alsace

(FMNA), 8 rue Sainte Elisabeth, F-67000 Strasbourg, France.

4. University of Strasbourg Institute for Advanced Study, 5 allée du Général Rouvillois, F-67083

Strasbourg, France.

KEYWORDS: coatings, polymers, enzymes, electrophoretic, electrodeposition, carbon nanotubes, nanoparticles 


\section{ABSTRACT}

Macromolecular coatings play an important role in many technological areas, ranging from car industry to biosensors. Among the different coating technologies, electrochemically triggered processes are extremely powerful because they allow in particular spatial confinement of the film buildup up to the micrometer scale on microelectrodes. Here, we review the latest advances in the field of electrochemically triggered macromolecular film buildup processes performed in aqueous solutions. All these processes will be discussed and related to their several applications such as corrosion prevention, biosensors, antimicrobial coatings, drug-release, barrier properties and cell encapsulation. Special emphasis will be put on applications in the rapidly growing field of biosensors. Using polymers or proteins, the electrochemical buildup of the films can result from a local change of macromolecules solubility, self-assembly of polyelectrolytes through electrostatic/ionic interactions or covalent cross-linking between different macromolecules. The assembly process can be in one step or performed step-by-step based on an electrical trigger affecting directly the interacting macromolecules or generating ionic species. 


\section{INTRODUCTION}

Functional materials are predicted to have an enormous impact on many aspects of society, including next generation health care and energy-related technologies. Control of the interactions between material surfaces and their environment can be achieved by tailoring their surface properties, especially through the application of coatings. Macromolecular coatings play a major role in many technological areas ranging from the car industry to biosensors, membrane coating or chromatography columns. This has triggered the development of numerous deposition processes, ${ }^{1-3}$ the simplest one being macromolecular adsorption. More known methods are for example the Langmuir-Schaefer film transfer ${ }^{4-5}$ or the layer-by-layer (LbL) deposition of polyelectrolytes resulting in what is known as "polyelectrolyte multilayers". ${ }^{6-8}$ Yet, most of these techniques lead to a uniform deposition and do not allow for spatially resolved film buildups which require the use of spatially localized triggers. To achieve such a spatial buildup, two main triggers are used: light and redox reactions at electrodes. Here, we will review macromolecular film buildup processes triggered by electrochemical means and performed in aqueous solution. Such coating processes are among the first ones which were used industrially at a large scale. In particular, car industry developed the electrodeposition of paint used to prevent corrosion. With the development of miniaturized (bio)sensors, electrochemically triggered buildup processes have found new applications. This review is divided in three sections related to the three categories of electrochemical buildup processes: (1) electrodeposition of macromolecules that result from their change of solubility near the electrode. Such a solubility change is often due to an induced local $\mathrm{pH}$ change near the electrode; (2) electrodeposition of polyelectrolytes on electrodes. In this case, polyelectrolytes are deposited through electrostatic or ionic interactions and (3) electrodeposition of polymers through covalent bond formation (Figure 1). 




Figure 1. Schematic representation of the main processes of macromolecular film buildup triggered by electrochemical means performed in aqueous solution based on precipitation of macromolecules by change of solubility, ionic self-assembly of polyelectrolytes through electrostatic or ionic interactions and covalent bonds formation between macromolecules. Besides a change of the electrostatic surface charge of the electrode, the application of a current (or a potential) induces the generation of a gradient of $\mathrm{H}^{+}, \mathrm{OH}^{-}$, metal ions or oxidized molecules which interact or react with the macromolecules present in solution. Allowing the encapsulation of enzymes, nanomaterials, drugs or cells, these processes are applied in several applications, such as biosensors, corrosion prevention, antimicrobial coatings, drug-release, barrier properties and cell encapsulation. 
A large number of electrodeposition processes are based on the generation of chemical species (ions or redox molecules) at the electrode that then diffuse towards the solution. The film buildup is thus obtained by reaction or interaction between the electrogenerated species and the macromolecules. In analogy with morphogenic processes, such species can be called morphogens, a concept introduced in 1952 by Alan Turing in biological development. ${ }^{9}$ In each section of this review, the numerous applications of each process will be presented such as enzymatic and nonenzymatic biosensors, corrosion prevention, antimicrobial coatings, drug-release, barrier properties and cell encapsulation. Special emphasis will be put on applications in the rapidly growing field of biosensors.

1. Electrodeposition through macromolecule precipitation

1.1 Electrodeposition of paints and other polyelectrolytes

Principle. Electrodeposition of macromolecules through precipitation is a process that has been discovered almost a century ago and is now referenced as electrodeposition of paints. Some patents from the first half of the $20^{\text {st }}$ century describe examples of electropainting on conductive surfaces. ${ }^{10-12}$ All these processes were based on the deposition of natural resinous materials, such

as rubber. Finding no application in the industry, research on this topic was somehow forgotten. ${ }^{13}$ During the 1950s with the great development of the car industry, coating processes were greatly needed in order to protect metallic surfaces from rust. Thus between Ford Motor and several paint companies, parallel researches were made to develop water-soluble paints which could be electrodeposited. The electrodeposition of cathodic paints, i.e. polycations soluble at acidic $\mathrm{pH}$, is based on their deprotonation at basic $\mathrm{pH}$. A localized precipitation and deposition of the polymers is obtained by the formation of a $\mathrm{pH}$ gradient (hydroxide ions gradient) at the electrode due to water electrolysis below a potential of $-2 \mathrm{~V}$ (Figure 2). Electrodeposition of anodic paints were 
also developed using polyanions soluble at basic $\mathrm{pH}$ and insoluble at acidic $\mathrm{pH}$. In this case, a gradient of protons is generated by water electrolysis at 50-400 V. Cathodic paints are mainly used to prevent corrosion in car industry. ${ }^{14}$ Numerous papers and reviews, published at the end of the $20^{\text {th }}$ century, describe the fundamental aspects of the electrodeposition process ${ }^{15-19}$ and the chemistry of the paints and the binders. ${ }^{20-21}$

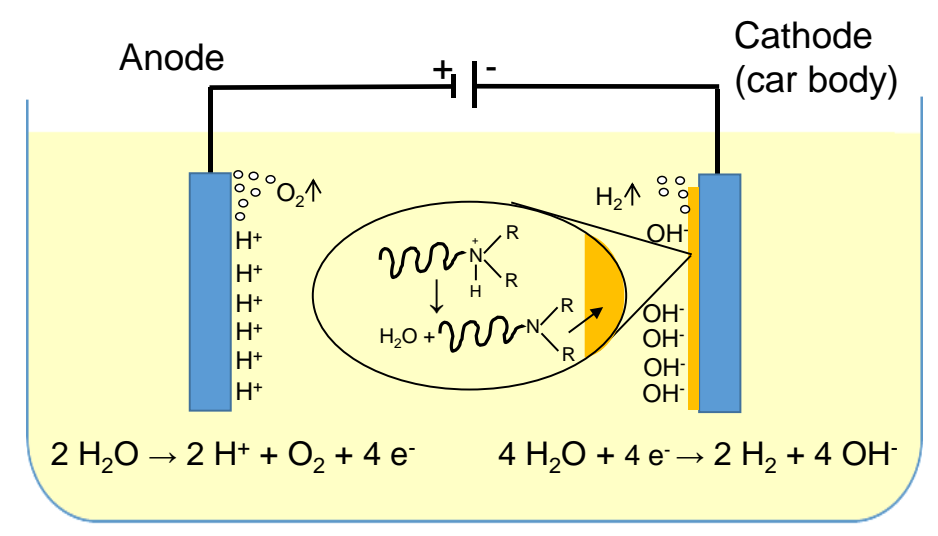

Figure 2. Mechanism of the deposition of a cathodic electrocoating.

In 2002, Payne and co-workers opened a new page in the field of electrodeposition of polymers by using chitosan, a natural polysaccharide, as cathodic paint. ${ }^{22}$ Chitosan is soluble at $\mathrm{pH}<\mathrm{pKa}$ $(\text { about } 6.3)^{23-24}$ due to protonation of the primary amino groups and insoluble at $\mathrm{pH}>\mathrm{pKa}$ (Figure 3a). The precipitation of chitosan in the vicinity of the electrode is obtained typically by generating a basic $\mathrm{pH}$ gradient by water electrolysis at $-2 \mathrm{~V}$ (Figure $3 \mathrm{~b}$ ). The deposition process can be divided in two parts: (i) the electrophoretic motion of charged chitosan chains towards the electrode under the electric field, ${ }^{25}$ and (ii) the chitosan precipitation due to $\mathrm{pH}$ change in the vicinity of the electrode. Using a microfluidic device under an optical microscope, the presence of a $\mathrm{pH}$ gradient ${ }^{26}$ has been confirmed near the electrode triggering the formation of a semi-crystalline chitosan gel. ${ }^{27}$ Electrochemically inactive, the chitosan gel is permeable to cationic and anionic probes. ${ }^{28}$ The 
deposited thickness is controlled by different parameters such as the time of deposition or the applied current density. ${ }^{22,29}$ The morphology (pores size and connection) of the gels can be tuned by changing the $\mathrm{pH}$, the salt concentration or the nature of the acidic solution used to solubilize chitosan, i.e. acetic acid, malonic acid or citric acid solution. ${ }^{30-31}$

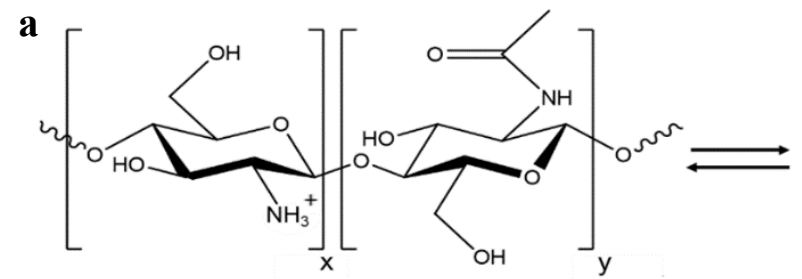

Soluble

b

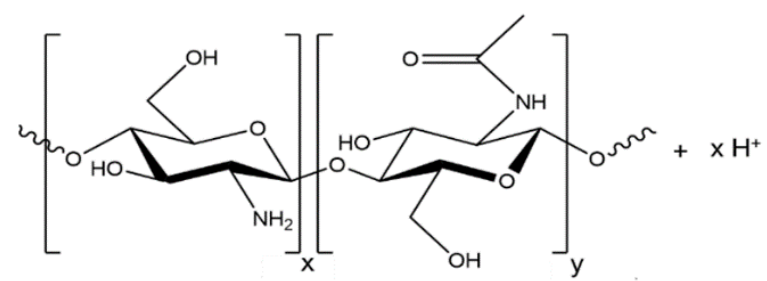

Insoluble

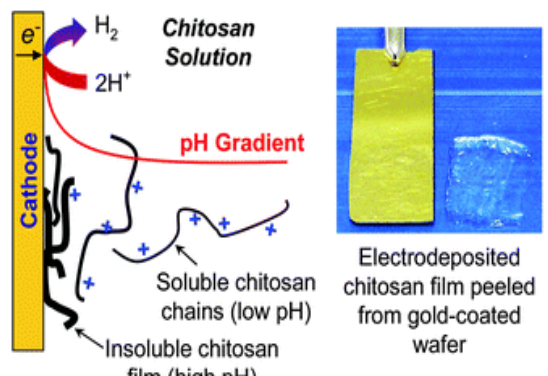

film (high pH)

Figure 3. (a) Chemical pathway between soluble and insoluble chitosan. (b) Mechanism of cathodic electrodeposition of chitosan and image of the obtained chitosan gel peeled from an electrode. Reproduced with permission from reference 31. Copyright 2013 Royal Society of Chemistry.

The spatial control of the deposition was shown using wire electrode, ${ }^{32}$ patterned template with an edge sharpness of 0.5-1.0 $\mu \mathrm{m}^{29,33-34}$ and confined micropores with a diameter of 3-8 $\mu \mathrm{m}$ (Figure 4). ${ }^{35}$ Using photoconductive cathodes to produce hydroxide ions, patterned chitosan depositions were obtained by patterned light illumination. ${ }^{36}$ Since 2008, Zhitomirsky and co-workers developed the electrodeposition using other biopolymers (alginate, ${ }^{37}$ hyaluronic acid ${ }^{38}$ ), polypeptides (poly(L-lysine), poly(L-arginine $))^{39}$ and synthetic polyelectrolytes. ${ }^{40-42}$ 
a



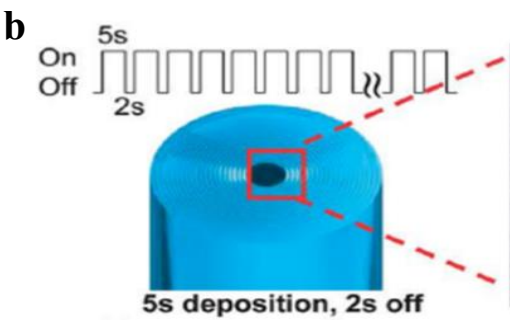
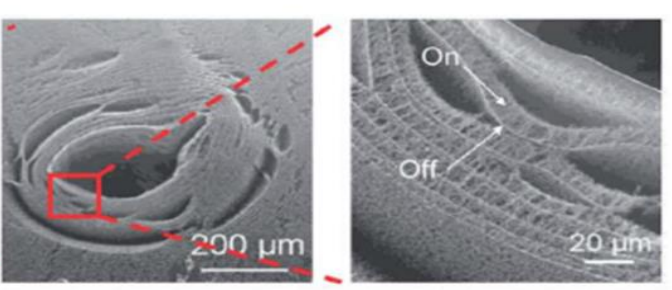

Figure 4. Spatially selective electrodeposition of (a) fluorescently labeled chitosan on a curved geometry pattern at a constant current of $3 \mathrm{~A} / \mathrm{m}^{2}$ for $120 \mathrm{~s}$. Reproduced with permission. ${ }^{33}$ Copyright 2009, Royal Society of Chemistry, and (b) of chitosan gel on a wire using on/off application of a current of $0.5 \mathrm{~mA}$. Reproduced with permission from reference 32 . Copyright 2014 Royal Society of Chemistry.

Enzymatic biosensing application. Enzymatic biosensors are analytical devices that associate a bioreceptor, which is an immobilized enzyme, and a transducer. The transducer converts the (bio)chemical signal resulting from the interaction between the analyte and the enzyme into an electrical signal proportional (or inversely proportional) to the analyte concentration. Oxidoreductases are mainly used due to their ability to catalyze oxidation or reduction reactions by transfer of electrons. In 2002 using commercially available anodic paints, Schuhmann and coworkers found new applications of paint electrodeposition in the field of enzymatic biosensors. ${ }^{43}$ Paint electrodeposition processes allowed to co-deposit enzymes by physical entrapment, in copolymer acrylate/acrylate ester (anodic paint) ${ }^{43-48}$ or copolymer vinyl imidazole/dimethylaminoethyl methacrylate (cathodic paint) coatings. ${ }^{49-52}$ Glucose oxidase $(\mathrm{GOX})^{43-44,46-47,49-51,53-54}$ was the first immobilized enzyme for glucose monitoring. The monitoring is based on the detection of $\mathrm{H}_{2} \mathrm{O}_{2}$ generated by the oxidation of glucose by the enzyme (eq 1). This detection is done by measuring the current intensity during the oxidation of $\mathrm{H}_{2} \mathrm{O}_{2}$ at 
$0.6 \mathrm{~V}$ (vs $\mathrm{Ag} / \mathrm{AgCl})$. Alcohol oxidase (AOX) was immobilized to titrate ethanol using the same electrochemical detection of $\mathrm{H}_{2} \mathrm{O}_{2}$, produced as secondary product when ethanol is oxidized in acetaldehyde by the enzyme. ${ }^{55}$ However due to limited stability of AOX-based sensors at high working potential, AOX and horseradish peroxidase (HRP) bi-enzyme sensors were designed for alcohol sensing at lower working potential. ${ }^{52,56}$ A first layer of HRP was immobilized on the electrode before immobilization of a second layer of AOX using the electrodeposition process. The enzymatic oxidation of ethanol by AOX generates $\mathrm{H}_{2} \mathrm{O}_{2}$ which is reduced by $\mathrm{HRP}$ (eqs 2-3). The generated current, proportional to the concentration in ethanol, is measured by application of $-0.05 \mathrm{~V}(\mathrm{vs} \mathrm{Ag} / \mathrm{AgCl})$.

$$
\begin{aligned}
& \text { Glucose }+\mathrm{O}_{2}+\mathrm{GOX}(\text { ox }) \rightarrow \text { D-glucono- } \delta \text {-lactone }+\mathrm{H}_{2} \mathrm{O}_{2}+\mathrm{GOX}(\text { red }) \\
& \text { Ethanol }+\mathrm{O}_{2}+\mathrm{AOX}(\text { ox }) \rightarrow \text { acetaldehyde }+\mathrm{H}_{2} \mathrm{O}_{2}+\text { AOX }(\text { red }) \\
& \mathrm{H}_{2} \mathrm{O}_{2}+2 \mathrm{H}^{+}+\mathrm{HRP}(\text { red }) \rightarrow \mathrm{H}_{2} \mathrm{O}+\mathrm{HRP}(\text { ox })
\end{aligned}
$$

Another bi-enzyme system was developed for ATP sensing by simultaneous immobilization of GOX and hexokinase (HEX) ${ }^{57}$ In the presence of a known concentration of glucose, an analytical signal (using $\mathrm{H}_{2} \mathrm{O}_{2}$ detection) is measured due to its reduction by GOX (eq 1). When ATP is added to the solution, glucose is also consumed by HEX (eq 4). A competitive consummation of glucose is obtained decreasing the quantity of glucose available for GOX. Thus, the analytical signal due to glucose decreases proportionally to the quantity of ATP present.

$$
\text { Glucose + ATP + HEX (ox }) \rightarrow \text { glucose-6-P +ADP + HEX(red) }
$$

In the above studies, the electron transfer between the entrapped redox enzyme and the electrode occurs via free-diffusing redox mediators, i.e. the enzymatically generated $\mathrm{H}_{2} \mathrm{O}_{2}$. Generally, direct 
electron transfer between the enzyme and the electrode is most of the time prevented due to the deeply buried prosthetic group in the enzyme. In order to improve the electron transfer, osmium functionalized polymers, redox polymers, were co-deposited with several enzymes, such as quinohemoprotein alcohol dehydrogenase, ${ }^{48}$ AOX/HRP bi-enzyme system, ${ }^{52,}{ }^{56} \mathrm{GOX},{ }^{54,58-59}$ Laccase, ${ }^{59-60}$ cellobiose dehydrogenase, ${ }^{58}$ pyrroloquinoline quinone-dependent glucose dehydrogenase. ${ }^{58,61-62}$ In this last case, mediated electron transfer is obtained by electron hopping through consecutive oxidation/reduction reactions of osmium moieties (Figure 5). Recently, Plamper published a review which categorizes the different basic mechanisms for electrochemical switching of redox-active polymers, leading to conformational and solubility changes. ${ }^{63}$

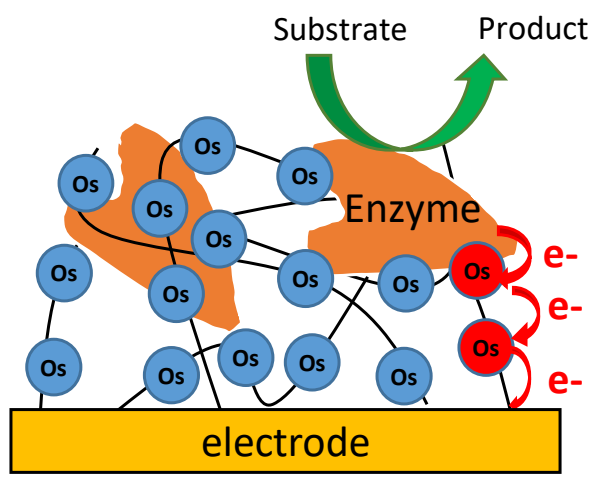

Figure 5. Schematic representation of electron hopping mechanism in osmium functionalized polymer deposited by electrodeposition.

The operating stability of electrodeposited redox polymer films was improved by electrochemically induced crosslinking of the deposited films. ${ }^{59}$ Epoxy functionalized redox polymers and protected thiol (or amine) bifunctional spacers were co-deposited by application of anodic potential pulse sequence. The generated $\mathrm{pH}$ gradient allowed the concomitant electrodeposition of the redox polymer and the deprotection of the spacers leading to the 
crosslinking between epoxy and thiol (or amine) moieties. Laccase and GOX were successfully immobilized by this process leading to an improved operation stability of the biosensor over two days. Different types of electrodes were functionalized using the electrodeposition of paints: such as micro-electrodes (i.e. four-bands Pt array 1-mm length; $25-\mu \mathrm{m}$ width; $25-\mu \mathrm{m}$ distance), ${ }^{43}$ tiplike electrodes (i.e. home-made platinized pipet tip) ${ }^{44}$ or porous electrodes. ${ }^{47,54}$ Porous electrodes were prepared either by electrodeposition of gold on a colloidal crystal template (using silica spheres) followed by its dissolution ${ }^{47}$ or by nanoparticle lithography on a layered gold/ $\mathrm{Si}_{3} \mathrm{~N}_{4}$ insulator/gold structure, nanoparticles being used as a shadow mask. ${ }^{54}$ Enzyme loaded electrodeposited films can also be used for biofuel cell applications allowing reproducible and localized enzyme deposition. ${ }^{64-66}$

Electrodeposited chitosan films were widely used to develop biosensors by co-deposition with enzymes ${ }^{67}$ and various inorganic compounds. The first chitosan based biosensors were based on co-electrodeposition of chitosan with GOX and inorganic nanomaterials such as gold nanoparticles, ${ }^{68-73}$ carbon nanotubes, ${ }^{74-76} \mathrm{MnO}_{2}$ particles ${ }^{77-78}$, nickel nanoparticles ${ }^{79}$ and graphene oxide. ${ }^{80-81}$ The co-deposition of inorganic nanomaterials improves biosensor properties by promoting electron transfer. The sensitivity and stability of the response of HRP or GOX-based biosensors were also improved by co-incorporation of highly conductive ionic liquids ${ }^{82-83}$ and Prussian Blue, an efficient redox mediator for selective reduction of $\mathrm{H}_{2} \mathrm{O}_{2} \cdot{ }^{84-85}$ Acetylcholine, choline, polyphenol, superoxide anions and adrenaline biosensors were created by co-deposition of chitosan with acetylcholine esterase, ${ }^{86-91}$ choline oxidase, ${ }^{92}$ laccase,${ }^{93}$ superoxide dismutase ${ }^{94}$ and tyrosinase. ${ }^{95}$ GOX-chitosan microspots were designed by generating local $\mathrm{pH}$ gradients using scanning electrochemical microscopy. ${ }^{96}$ This method may facilitate the construction of a microfabricated biosensor based on spatial segregation of enzymes on a homogeneous support. 
Co-electrodeposition of chitosan and two different inorganic components can be done step-by-step to obtain chitosan/Prussian Blue and chitosan/gold nanoparticles double layers before deposition of GOX and $\beta$-glucanase mixture solution. The obtained sensor allowed monitoring $\beta$-glucan, a natural polymer of D-glucose present in cell walls of yeast or fungi through its oxidation by $\beta$ glucanase into glucose which is further oxidized by GOX. ${ }^{97}$ To monitor glucose at low working potential, GOX/HRP bi-enzyme sensors were developed by one step co-electrodeposition of chitosan, GOX, HRP and Concanavalin A from a mixed solution..$^{98}$ Concanavalin A was used as a linker between the enzymes and chitosan due to its affinity with glycoconjugates. Electrodeposited chitosan can also be used as a platform. Indeed, $\mathrm{H}_{2} \mathrm{O}_{2}{ }^{99}$ and glucose ${ }^{100}$ sensors were developed by adsorption of HRP (with gold nanoparticles) and GOX on previously electrodeposited chitosan, respectively. An amperometric $\mathrm{H}_{2} \mathrm{O}_{2}$ biosensor was designed by codeposition of alginate with HRP, followed by polyvinyl butyral layer to prevent enzyme leakage. ${ }^{101}$

Non-enzymatic biosensing applications. Organic molecules, such as positively charged metalloporphyrins, were co-deposited with negatively charged polymers, using electrodeposition of paints, for nitric oxide (NO) sensing. The detection was based on NO oxidation by metalloporphyrin molecules. ${ }^{45}$ Miniaturized potentiometric and voltammetric $\mathrm{pH}$ sensors were developed by electrodeposition of two redox polymers, one with covalently linked osmium complexes as $\mathrm{pH}$ independent redox species and the other containing a $\mathrm{pH}$-dependent phenothiazine moieties on gold microelectrodes. ${ }^{102}$ The peak potentials for both redox immobilized species were determined from the square-wave voltammograms. Using the $\mathrm{pH}$ independent polymer as internal reference, the peak potential difference of the $\mathrm{pH}$-dependent redox polymer allowed the determination of the $\mathrm{pH}$ in a reproducible manner. It should be noted that Janus particles were obtained by bipolar electrodeposition of paints, where the $\mathrm{pH}$ gradient was 
localized at the surface of conducting particles in suspension under an electric field of $71 \mathrm{~V} / \mathrm{cm} .{ }^{103}$ Janus anisotropic particles could be used in applications such as e-paper. ${ }^{104}$

Non-enzymatic biosensors were also developed by co-deposition of chitosan and different inorganic components. Manganese dioxide nanowires were deposited with chitosan for $\mathrm{drug}^{105}$ and cysteine sensing. ${ }^{106}$ Cysteine sensing is based on the redox reaction which takes place between $\mathrm{MnO}_{2}$ and cysteine to form a disulfide bond between two cysteine molecules and $\mathrm{MnO}(\mathrm{OH})$, easily protonated in water (eq 5). Protonated $\mathrm{MnO}(\mathrm{OH})$ can be electrooxidized back to $\mathrm{MnO}_{2}$ by applying a potential of $0.5 \mathrm{~V}$ (vs SCE) (eq 6), the measured current being proportional to cysteine concentration.

$$
\begin{aligned}
& 2 \mathrm{MnO}_{2}+2 \mathrm{CySH} \rightarrow 2 \mathrm{MnO}(\mathrm{OH})+\mathrm{Cy}-\mathrm{S}-\mathrm{S}-\mathrm{Cy} \\
& \mathrm{MnO}(\mathrm{OH})-\mathrm{H}^{+} \rightarrow \mathrm{MnO}_{2}+2 \mathrm{H}^{+}+2 \mathrm{e}-
\end{aligned}
$$

Trichloroacetic acid (TCAA), a toxic pollutant found in industrial waste, sensor was designed by co-deposition of chitosan and silver nanoparticles. Low detection limit and fast current response of TCAA reduction were obtained due to a good electron hopping in silver nanoparticles and a favorable electrostatic interactions between oppositely charged TCAA and chitosan. ${ }^{107} \mathrm{NO}$ is a free-radical messenger involved in a wide range of physiological and pathological processes. In vivo microsensor for detection of $\mathrm{NO}$ in the brain was developed by co-deposition of chitosan, hemin (a metalloporphyrin) and functionalized multi-wall carbon nanotubes. ${ }^{108} \mathrm{NO}$ was measured by electrochemical reduction at $0.762 \mathrm{~V}$ (vs $\mathrm{Ag} / \mathrm{AgCl}$ ) using square wave voltammetry, which offers the advantage of high sensitivity and the chemical resolution needed. Direct electron transfer was ensured by $\mathrm{Fe}(\mathrm{II}) / \mathrm{Fe}(\mathrm{III})$ couple of hemin and carbon nanotubes. Biocompatible carbon nanofiber-chitosan materials were designed for cytosensing. This biosensor is based on the 
measurement of the impedance signal which depends on the amount of adherent cells. ${ }^{109}$ Molecularly imprinted hybrid films were developed to detect p-nitrophenol (p-NP), a toxic substance extensively used in chemical industry. ${ }^{110}$ Simultaneous electrodeposition of chitosan, copolymerization of phenyltrimethoxysilane (PTMS) and electroreduction of $\mathrm{HAuCl}_{4}$ salt into gold nanoparticles were performed in the presence of p-NP. Thanks to H-bond interactions, p-NP molecules interact with chitosan and are further removed from the electrodeposited coating by cyclic voltammetry (CV) (Figure 6). The applied voltage range of CV causes the cycle of reduction/oxidation of $\mathrm{p}-\mathrm{NP}$, disrupting the strong interactions of $\mathrm{p}-\mathrm{NP}$ with the binding sites and favoring the template removal. After further incubation in different p-NP solutions, differential pulse voltammetry was used to measure the current intensity at the reduction potential of p-NP $(0.12 \mathrm{~V}$ vs SCE) and to obtain a linear calibration curve versus p-NP concentration. An improved sensorial detection range and detection limit were obtained with p-NP imprinted hybrid films in comparison to non-imprinted film (i.e. chitosan/PTMS/gold nanoparticles) thanks to the binding of $\mathrm{p}-\mathrm{NP}$.

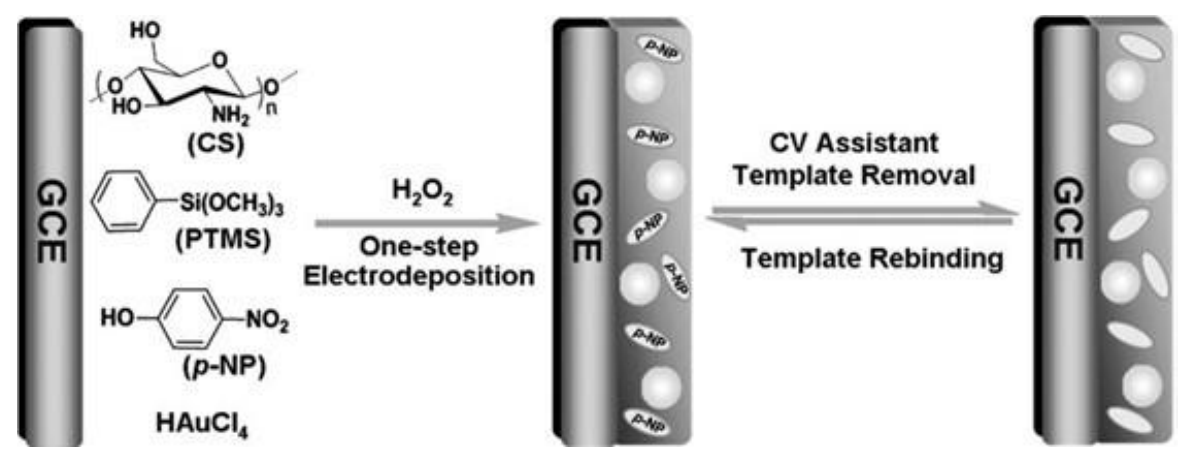

Figure 6. Schematic representation of the fabrication protocol imprinted Chitosan/PTMS/AuNPs on glassy carbon electrode (GCE) for sensing p-NP. Reproduced with permission from reference 110. Copyright 2013 Royal Society of Chemistry. 
Different immunosensors were developed by post-functionalization of electrodeposited chitosan with antibodies, oligonucleotides, viruses, phenol/catechol bearing molecules and proteins using physical adsorption or grafting by chemical, electrochemical or enzymatic means. Label free immunosensors for the detection of Hepatitis B surface antigen were designed by physical adsorption of Hepatitis B antibody on 3D porous chitosan membrane ${ }^{111}$ and on ferrocene functionalized chitosan films. ${ }^{112}$ Antigen concentration was measured through the decrease of amperometric response due to the formation of the antibody/antigen complex layer. This complex layer blocks the transfer of electrons provided by ferrocyanide present in solution ${ }^{111}$ or grafted ferrocene $^{112}$ under electrochemical stimulation. Glutaraldehyde chemistry applied on electrodeposited chitosan was used to immobilize DNA to obtain biochips ${ }^{113-115}$ or sensors able to detect DNA hybridization by the mass change of a microcantilever. ${ }^{116}$ Tobacco mosaic virus, genetically modified, was assembled selectively on microelectrodes through nucleic acid hybridization on chitosan for the development of viral templates. ${ }^{117}$ By electrodeposition of biotinylated chitosan, streptavidin was immobilized on microelectrodes allowing spatial selectivity of biotinylated protein assemblies, i.e. biotinylated Protein A allowing further deposition of fluorescently-labeled antibodies. ${ }^{118}$ After its electrodeposition, chitosan can be oxidized using electrochemistry for further grafting of avidin, protein $\mathrm{G}$ and green fluorescent protein. ${ }^{119}$ Indeed by application of an anodic potential of $0.9 \mathrm{~V}(\mathrm{vs} \mathrm{Ag} / \mathrm{AgCl})$ in the presence of $\mathrm{NaCl}$, reactive mediators, $\mathrm{HOCl}$ and $\mathrm{OCl}^{-}$, are formed and oxidize chitosan creating aldehyde moieties which can further react with primary amines of proteins. Fluorescently labeled azide tagged bovine serum albumin was covalently fixed on electrodeposited alkyne functionalized chitosan, by $\mathrm{Cu}(\mathrm{I})$ catalyzed Huisgen reaction, where $\mathrm{Cu}(\mathrm{I})$ was generated at the electrode from reduction of $\mathrm{Cu}(\mathrm{II}) .{ }^{120}$ Phenol or catechol moieties have been grafted on electrodeposited chitosan by applying an anodic 
potential by making use of their properties in oxidative state to react with amino groups of chitosan. ${ }^{121-123}$ Besides improving the mechanical properties, ${ }^{124}$ the presence of catechol moieties amplify the electrochemical signal of redox probes in contact with the chitosan gel (Figure 7). ${ }^{121}$, 125 This property was used to detect pyocyanin, a redox active bacterial metabolite ${ }^{126}$ and clozapine, an antipsychotic drug. ${ }^{127-130}$

(a)

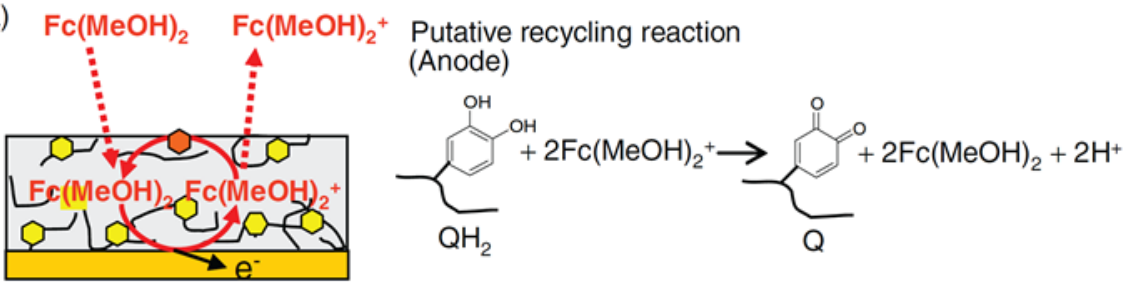

(b)

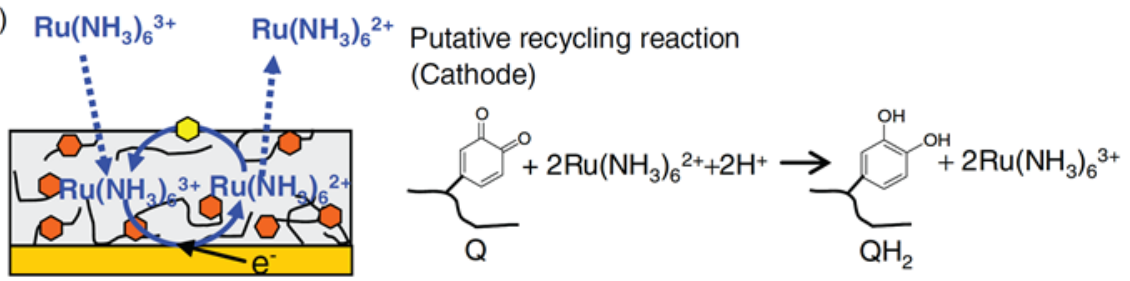

Figure 7. Proposed mechanism for amplification of mediator-based electrochemical currents by catechol-modified chitosan films: two mediators, (a) ferrocene dimethanol $\mathrm{Fc}(\mathrm{MeOH})_{2}$ and (b) ruthenium hexaamine $\mathrm{Ru}\left(\mathrm{NH}_{3}\right)_{6}{ }^{3+}$, engage oxidative and reductive redox-cycling mechanisms between the phenolic film $\left(\mathrm{QH}_{2} / \mathrm{Q}\right)$ and ITO electrode. Reproduced with permission from reference 121. Copyright 2014 John Wiley and Sons.

Other biomedical applications. A multi-domain fusion protein, named HLPT, was immobilized covalently on previously electrodeposited chitosan to produce a bacterial signaling molecule in order to electronically induce collective bacterial behavior. ${ }^{131}$ This covalent functionalization was obtained enzymatically using tyrosinase and tyrosine containing proteins. ${ }^{115,}{ }^{132}$ The principle is based on an adsorbed tyrosinase layer on the chitosan film which selectively converts tyrosine 
residues of proteins into reactive o-quinones. The "activated" proteins can then undergo grafting reactions with the nucleophilic amines of chitosan. Organized magnetic nanoparticles platform was developed for the immobilization of antibody-functionalized magnetic beads to capture specific pathogens and collect them by magnetic removal (Figure 8).

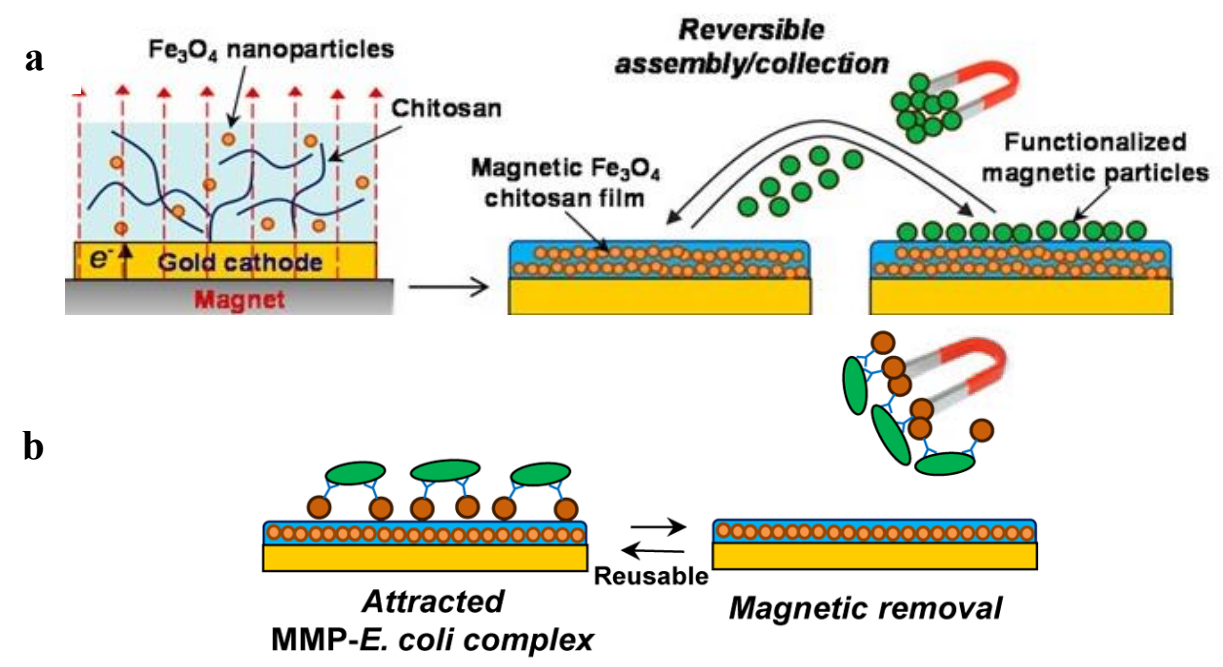

Figure 8. Schematic representation of (a) the co-electrodeposition of chitosan (dark blue chains) and magnetic $\mathrm{Fe}_{3} \mathrm{O}_{4}$ nanoparticles (orange spheres) in the simultaneous imposition of a magnetic field leading to organized nanoparticles. This magnetic $\mathrm{Fe}_{3} \mathrm{O}_{4}$ chitosan film is able to reversibly capture magnetic microparticles (green spheres). (b) This platform can be used to collect and to release E. Coli (green ellipsoid) through the reversible immobilization of antibody (anti-E. Coli) functionalized magnetic microparticles (MMP-E coli, brown spheres). Reproduced with permission from reference 133. Copyright 2015 American Chemical Society.

This platform was obtained by the electrodeposition of chitosan films in the presence of magnetic nanoparticles by applying both electric and magnetic fields. ${ }^{133}$ Microbial fuel cells are devices in which bacteria consume water-soluble waste (such as glucose, ethanol and acetate) to generate electrons. Co-electrodeposited chitosan/alginate/Prussian Blue films offer (i) a biocompatible 
matrix for the growth of microorganisms and (ii) a good electron transfer for the development of microbial fuel cell. ${ }^{134}$ Nanoparticle platforms were developed by co-deposition of chitosan with fluorescently labeled latex nanoparticles, ${ }^{135} \mathrm{ZnO}$ particles, ${ }^{136} \mathrm{ZnS}$ quantum dots, ${ }^{137}$ carbon dots ${ }^{138}$ to develop fluorescent or photoluminescent coatings with tunable intensity depending on the deposition parameters, such as deposition time. Alternating current electrodeposition was demonstrated to be a suitable technique to deposit uniform poly(acrylic acid)- $\mathrm{TiO}_{2}$ composite coatings on conductive materials. ${ }^{139}$

The electrodeposition of natural polymers, such as chitosan or alginate, allows the development of biocompatible coatings for stainless steel or titanium implants. Biocompatibility tests were performed on chitosan/alginate layered coatings, obtained by alternated electrodeposition of chitosan and alginate, showing a suitable cell proliferation. ${ }^{140}$ Electrodeposited blends of chitosan and poly(ethylene oxide) $)^{141}$ or gelatin ${ }^{142}$ are promising candidates for implant functionalization with improved mechanical properties compared to chitosan. Co-electrodeposited chitosan/carbon nanotube films enhance cellular adhesion. ${ }^{143}$ Biocompatible hybrid coatings were developed by electrodeposition of chitosan with hydroxyapatite (HAp), the major mineral constituent of bones ${ }^{144-146}$ and bioactive glass, ${ }^{147-150}$ which favor the formation of HAp in contact with physiological fluids. In order to reduce corrosion, chitosan co-deposited with $\mathrm{HAp},{ }^{151-152} \mathrm{CaSiO}_{3}$ particles, ${ }^{153}$ carbon nanotubes, ${ }^{154-155}$ hexagonal boron nitride $/ \mathrm{TiO}_{2}{ }^{156}$ and halloysite nanotubes ${ }^{157}$ act as protective layers against ion diffusion towards nitinol ${ }^{154}$ and stainless steel surfaces. ${ }^{152,155-157}$ Other composite films, obtained by electro-codeposition of carbon nanotubes/alginate, ${ }^{154}$ halloysite/HAp/hyaluronic acid, ${ }^{158} \mathrm{HAp} /$ alginate, ${ }^{37} \mathrm{TiO}_{2} /$ alginate/ bioactive glass ${ }^{159}$ and cellulose nano-crystals/alginate, ${ }^{160}$ were also developed for corrosion protection of medical implants. Antimicrobial properties of chitosan gels were obtained by incorporation of silver 
nanoparticles, ${ }^{161-164}$ antibiotics, ${ }^{165}$ or antibiotics in combination with graphene oxide ${ }^{166}$ or with bioglass. ${ }^{167}$ Drug-release surfaces were developed by co-deposition of insulin loaded inorganic nanoplatelets, ${ }^{168}$ ibuprofen, ${ }^{169-170}$ gelatin/ampicilin ${ }^{171}$ and an antiseptic. ${ }^{172}$ The release is obtained by application of a potential (typically between -5 and $+5 \mathrm{~V}$ ) ${ }^{168}$ or by gel degradation ${ }^{171}$ or swelling ${ }^{172}$ in PBS. Antibiotic loaded polymeric microspheres/alginate electrodeposited layers can be used as drug-delivery coatings. ${ }^{173} \mathrm{ZnO} /$ alginate/bioactive glass coatings have both antimicrobial and corrosion protection properties. ${ }^{174}$

\subsection{Electrogelation of silk}

Principle. The electrogelation of silk, obtained from silkworm, has been developed using high potentials (up to $30 \mathrm{~V}$ ). ${ }^{175-176}$ By applying a constant electric potential, silk gels were deposited around the positive electrode (anode). ${ }^{175}$ The gel, stable when the electrical potential is stopped, can be dissolved by reversing the polarity of the working electrode while a new gel is created on the counter electrode. Silk fibroin is a high molecular weight block copolymer made of heavy and light chains linked by a single disulfide bond. ${ }^{177}$ The heavy chain consists of alternating arrays of 12 repetitive hydrophobic peptide domains, rich in alanine and glycine residues, and 11 small hydrophilic charged amorphous domains, rich in acidic groups. ${ }^{178}$ For a pH above its $\mathrm{pI}(4.2)$, silk protein is negatively charged and intermolecular self-assembly is prevented by electrostatic repulsion. When the $\mathrm{pH}$ value decreases by water electrolysis, protonation of acidic groups enables intermolecular self-assembly of silk's macromolecules. ${ }^{179}$ These gels exhibit spherical micellar structures obtained from the assembly of $10 \mathrm{~nm}$ diameter particles into several hundreds of $\mathrm{nm}$ spheres which in turn assemble into large microspheres (Figure 9). ${ }^{180}$ Theoretical finite-element electro-diffusion models using classic diffusion and ion migration equations under an electric potential support experimental $\mathrm{pH}$ measurement. ${ }^{181}$ These models confirm that silk electro-gel 
construction is governed by the proton gradient generated from the electrode. Such gels can be deposited on different electrode materials such as copper, aluminum, gold or platinum with various geometries. ${ }^{175} \mathrm{~A}$ thin transparent film with no underlying surface was obtained by using a ringshaped electrode. ${ }^{182}$ This fabrication process allows to confer three dimensionality and crystallinity to the gels. Their mechanical properties can be tuned by varying the time of application or the intensity of the electric potential. ${ }^{183-184}$

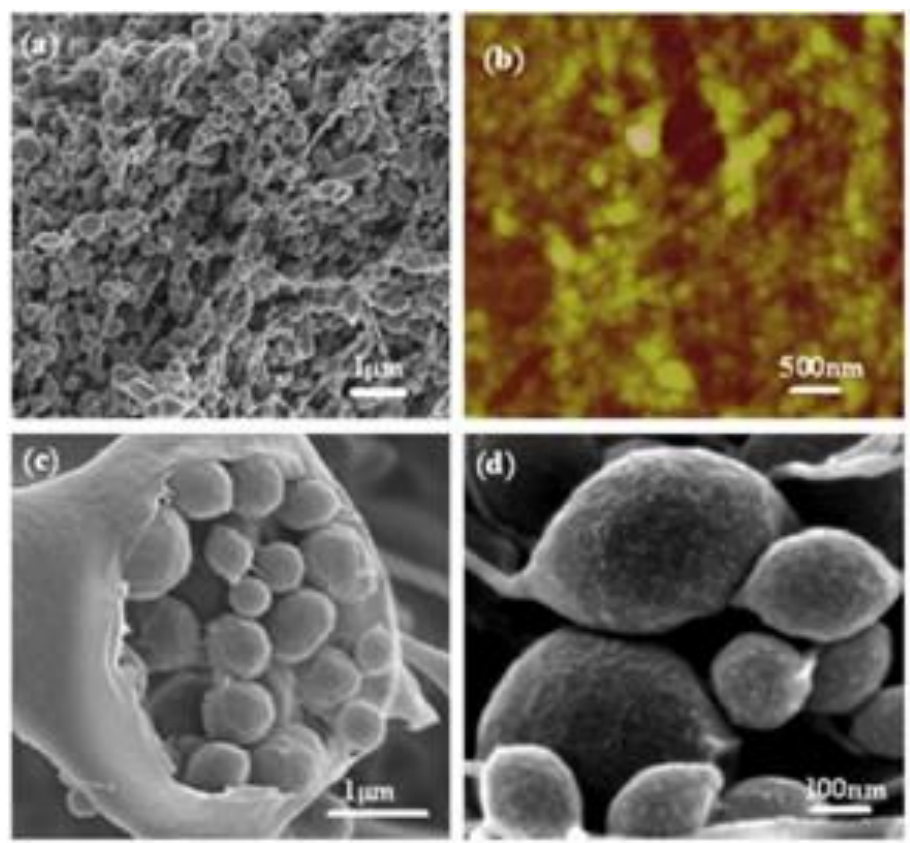

Figure 9. Morphology of electrodeposited silk gels observed by (a) scanning electron microscopy (SEM) and (b) atomic force microscopy. SEM (c) image of the inside structure of large microspheres and (d) magnified image of its inner part. Reproduced with permission from reference 180. Copyright 2011, Elsevier.

Applications. Mainly in random coil conformation, silk fibroin assembled in the gels are lacking thermal and mechanical stability. In order to improve their stability for biomedical applications, cross-linking of the gels was obtained chemically by using glutaraldehyde and physically by 
inducing $\beta$-sheet cross-links through ethanol dehydration. ${ }^{185}$ Very recently, these gels were studied as potential coatings for bone implants. ${ }^{186}$ To add an antibacterial activity, silk fibroins were chemically modified by tetracycline, a globally positively charged antibiotic. The obtained positively charged functionalized silk was deposited on a titanium cathode. ${ }^{187}$

\subsection{Electroprecipitation of enzymes}

Electroprecipitation of enzymes is a process based on the application of an electric potential to induce the precipitation of an enzyme on the surface of an electrode. Two different processes are described in the literature: the electrochemical and the electrophoretic depositions. Both are based on the electrolysis of water which generates a proton gradient leading to the aggregation and precipitation of enzymes at a $\mathrm{pH}$ close to its isoelectric point (pI). Both processes are summarized in exhaustive reviews ${ }^{188-189}$ and will only briefly be presented below.

Electrochemical deposition of enzymes. Electrochemical deposition of enzymes is based on the application of relatively low constant voltages (0-2V) in highly conductive solutions. Buffers with high ionic strength are often used to screen the charge of the enzyme which limits its motion in an electric field. Thus, only enzymes present in the vicinity of the electrode are deposited leading to thin coatings (few hundreds of $\mathrm{nm}$ ). Introduced by Wang et al. to create collagen-enzyme biocatalytic membranes, ${ }^{190}$ this process was applied for biosensing application by using various enzymes or proteins such as GOX, ${ }^{191-194} \mathrm{HRP},{ }^{195}$ laccase, ${ }^{196}$ or avidin, for further immobilization of biotinylated GOX. ${ }^{197}$ To improve the performance of the obtained coatings, enzymes were codeposited with other compounds such as anionic clay, ${ }^{198}$ carbon nanotubes, ${ }^{93,}{ }^{199}$ palladium nanoparticles ${ }^{200}$ or redox mediators/polymers. ${ }^{201-202}$ 
Electrophoretic deposition of enzymes. Electrophoretic deposition of enzymes is based on the electrophoretic motion of enzymes. In this process, high voltages (few hundreds of volts) are applied using low ionic strength solutions. ${ }^{189}$ To avoid heat and extensive evolution of water electrolysis, pulsed direct current (PDC) or alternating current (AC) are used. Having a high surface charge due to low charge screening, all the enzymes present in solution contribute to the film buildup. The obtained coatings are much thicker (several $\mu \mathrm{m}$ ) than the ones deposited by electrochemical deposition. Electrophoretic deposition of enzymes was introduced in 2009 by Ammam and coworkers using GOX. ${ }^{203}$ Different enzymes, such as $\beta$-galactosidase, ${ }^{204}$ laccase ${ }^{205-}$ 206 catalase ${ }^{206-207}$ or glutamate oxidase ${ }^{208}$ were immobilized using this process for biosensing and enzymatic biofuel cell applications. Electropolymerization of polypyrrole was performed after the electrophoretic deposition of GOX functionalized carbon nanotubes in order to obtain a stabilization of the assembled coating ${ }^{205}$ or before carbon nanotubes and glutamate oxidase deposition to prevent the diffusion of interfering molecules such as ascorbate, urate or acetaminophen. $^{208}$

2. Electrochemical deposition through polyelectrolytes self-assembly

2.1 Macromolecules deposition under the application of a constant potential

The influence of an electric potential on the adsorption of macromolecules was first studied on proteins $^{209-214}$ followed by polycations, such as poly(vinylpyrolidone $)^{215-216}$ and poly(L-lysine)grafted-poly(ethylene glycol). ${ }^{217}$ A surprising phenomenon was observed: positively charged proteins (and polycations) adsorbed on positively charged electrodes by application of an anodic potential. Furthermore, Van Tassel and coworkers highlighted a phenomenon of continuous deposition of different polycations, such as poly(L-Lysine) (PLL), poly(L-ornithine) and poly(allylamine) (PAH) during the application of a potential between 1.2 and $1.5 \mathrm{~V}(\mathrm{vs} \mathrm{Ag} / \mathrm{AgCl})$. 
This adsorption of polyelectrolytes on a charged electrode is not only driven by electrostatic interactions but also by weak interactions (van der Waals, close-range) and counterion condensation. ${ }^{218}$ Recently, Mergel et al. demonstrates the effect of polymer topology and molar mass on the electrodeposition of a quaternized polycation in the presence of hexacyanoferrate(II). In this case, a physically crosslinked polymeric film was obtained upon counterion switching, i.e. by oxidation of ferrocyanide into less charged ferricyanide. ${ }^{219}$ Polyelectrolyte multilayer films are obtained by the LbL process, based on the alternated deposition of polycations and polyanions on a surface. The application of a constant potential, typically between 1.0 and $2.0 \mathrm{~V}(\mathrm{vs} \mathrm{Ag} / \mathrm{AgCl}$ ), during the buildup of $\mathrm{PAH} /$ poly(styrene sulfonate) (PSS), ${ }^{220} \mathrm{PLL} / \mathrm{dex} \operatorname{tran}$ sulfate ${ }^{220}$ and PLL/DNA ${ }^{221}$ multilayers allows to tune their thickness. In 2012, Van Tassel wrote a review to make a summary of the influence of an electrical potential on the assembly and disassembly of polyelectrolyte films. ${ }^{222}$ Conductive neutral polymer, used for optoelectronic applications such as polymer light-emitting diodes or photovoltaic devices, can also be deposited under a constant voltage. Conductive multilayer of one component, a conductive polymer poly(3-hexylthiophene), was assembled by several applications of $10 \mathrm{~V}$ for $10 \mathrm{~min}$. A controlled thickness and high quality films were obtained with an improved crystallization compared to spin coated macromolecules. ${ }^{223}$ High crystallization and ordered arrangement of poly(3-hexylthiophene) allowed to obtained films with high conductance.

\subsection{Electric-Field Assisted Layer-by-Layer}

Principle. A derivate technique of the LbL process, the electric-field directed layer-by-layer assembly (EFDLA), was introduced by Gao and co-workers in $2002 .{ }^{224}$ Figure 10 shows a schematic illustration of the EFDLA, based on the enhancement of the electrostatic interactions between the polyelectrolytes and the surface by the application of alternated electric potential, 
typically between 0.5 and $1.5 \mathrm{~V}$, at each deposition step. ${ }^{225}$ When a polycation (linear poly(ethylene imine), LPEI) is brought in contact with the electrode, a negative potential is applied to render the surface negatively charged and to attract the polycation chains to the surface. When the polyanion (poly(acrylic acid), PAA) is in contact with the electrode, the applied potential is reversed to a positive value rendering the surface positively charged and attracting the negatively charged chains. Electroluminescent patterns were obtained by EFDLA of poly(diallyldimethylammonium chloride)/quantum dots on micro-electrodes by application of unfavorable (i.e. $0.6 \mathrm{~V}$ vs $\mathrm{Ag} / \mathrm{AgCl}$ ) and favorable (i.e. $1.4 \mathrm{~V} \mathrm{vs} \mathrm{Ag} / \mathrm{AgCl}$ ) potentials. ${ }^{226}$ EFDLA leads to larger amounts of adsorbed material on the surface than the classic LbL process due to the conformation (in coiled state) of deposited weak polyelectrolytes depending on the assembly $\mathrm{pH} .{ }^{227}$

$\mathbf{a}$

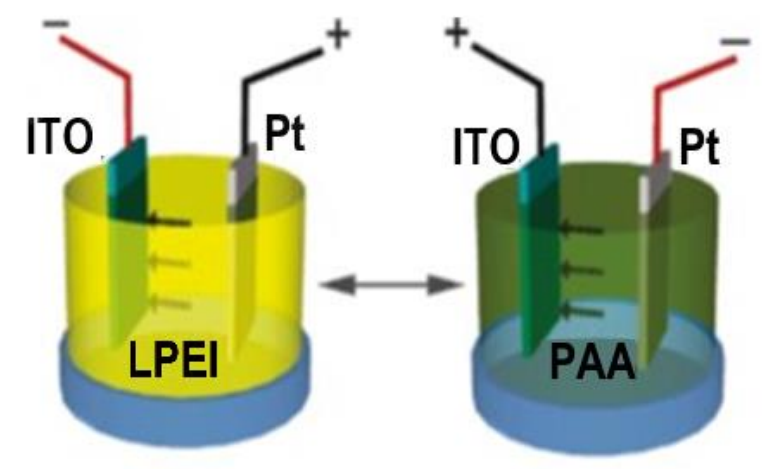

b

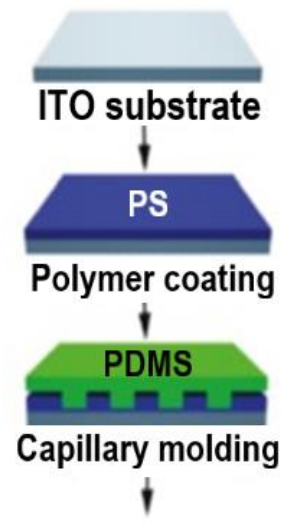

IIII

Residual layer removal

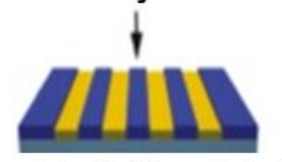

Electric field assisted LbL

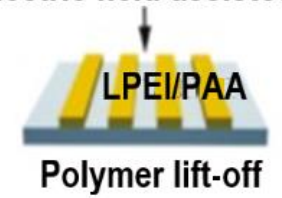

Figure 10. Schematic illustrations of (a) electric-field assisted layer-by-layer assembly of LPEI and PAA and (b) pattern formation. Reproduced with permission from reference 225. Copyright 2011 American Chemical Society.

Applications. Based on the electrocatalytic activity of quantum dots toward $\mathrm{CO}_{2}$ reduction, a photo-electrochemical device was developed to build quantum-dots/polycation multilayers on ITO 
electrodes. ${ }^{228}$ Enzyme and neutral red probe based multilayers were designed for biosensing applications ${ }^{229-230}$ and $\mathrm{pH}$ measurements, ${ }^{231}$ respectively. Polyamide reverse osmosis membranes were functionalized by PEI/PAA multilayers for isopropanol-water separation. In this case, the non-conductive membrane was dipped in the polyelectrolyte solution between two electrodes. A given constant voltage, between 0 and $10 \mathrm{~V}$, was applied to induce polyelectrolytes diffusion towards the membrane. ${ }^{232-233}$ Chitosan/lignosulfonate multilayer films with tunable wettability were deposited at an extremely high voltage $(4 \mathrm{kV}){ }^{234}$ This high voltage induces the reduction of the surface tension of the polymer solutions during the film buildup. At $0 \mathrm{~V}$, chitosan films deposited on lignosulfate are hydrophilic. The application of the electric field induces structural changes of the deposited chitosan which turns from hydrophilic to hydrophobic. ${ }^{234}$ Hydrogen, used as high-energy fuel by aerospace industry, can induce corrosion on stainless steel materials used for their storage. Self-assembled PEI/graphene oxide multilayers appeared to be a practical high barrier $\mathrm{H}_{2}$ material. ${ }^{235}$ When assembled under an electric field, enhanced $\mathrm{H}_{2}$ barrier properties were obtained due to an increase of the adsorbed amount of graphene oxide.

\subsection{Electro-self-assembly of polyelectrolytes through electrostatic interactions}

Very recently, our team introduced a new way to electrotrigger the assembly of oppositely charged polyelectrolytes in a one pot manner. ${ }^{236}$ For this purpose, a charge shifting polyanion, poly(allylamine dimethylmaleic acid) (PAHd), was synthesized by modification of PAH with dimethylmaleic functions. PAHd, negatively charged at basic $\mathrm{pH}$, can be hydrolyzed into positively charged PAH when the $\mathrm{pH}$ is decreased (Figure 11a). Mixed with PSS (polyanion) at basic $\mathrm{pH}$ in the presence of hydroquinone, PAHd does not form complexes due to electrostatic repulsion. The application of an anodic current (above $40 \mu \mathrm{A}$ ) induced the oxidation of hydroquinone leading to an acidic $\mathrm{pH}$ gradient in the vicinity of the electrode. This $\mathrm{pH}$ decrease 
induced the hydrolysis of PAHd into PAH in a confined area and triggered the localized assembly near the electrode of PAH and PSS through attractive electrostatic interactions (Figure 11b).


Self-assembly time at $90 \mu \mathrm{A}$ (min)
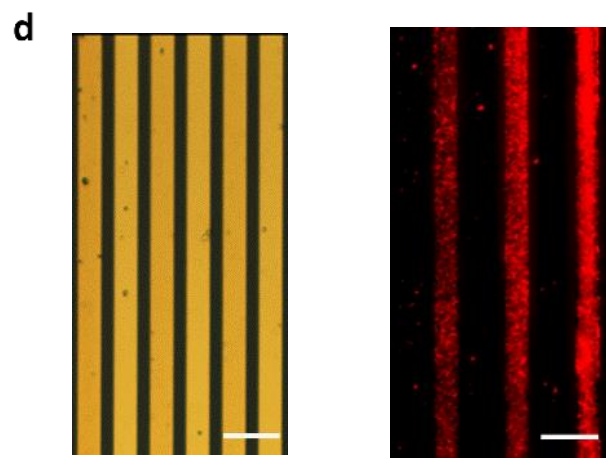

Figure 11. (a) Principle of the charge-shifting polyelectrolytes: PAHd (negatively charged) hydrolyzes under acidic conditions into PAH (positively charged). (b) Schematic representation of the one-pot self-assembly of PAH/PSS film (c) Enzymatic reaction rate of PAH/alkaline phosphatase films obtained for different self-assembly times and (d) optical microscope images of microelectrodes, in bright field and in fluorescence mode, where 3 electrodes were addressed to self-assemble PAH/rhodamine labelled alkaline phosphatase. The scale bar represents $25 \mu \mathrm{m}$. Reproduced with permission from reference 236. Copyright 2015 American Chemical Society.

When using an enzyme instead of PSS, i.e. PAHd/alkaline phosphatase/hydoquinone solution, an enzymatically active film was self-assembled whose activity increased with the deposition time (Figure 11c). This process is well suited for the specific functionalization of micro-electrodes 
opening the route towards miniaturized biosensors (Figure 11d). Another charge shifting polyanion, poly(allylamine citraconic acid) $(\mathrm{PAHc})^{237}$ was used solely in the presence of hydroquinone to self-assemble a one component films by application of an anodic current. The electrogenerated $\mathrm{pH}$ gradient induces a partial hydrolysis of PAHc leading to a polyampholyte solution that precipitates on the surface of the electrode. ${ }^{238}$

\subsection{Electro-self-assembly of polyelectrolytes through ionic activation}

Principle. Alginate forms a biocompatible hydrogel in the presence of divalent cations, such as calcium ions, which ionically crosslink its carboxylate groups. Self-assembly of alginate gels can be obtained by ionic activation from an electrode surface using the electrolysis of water (Figure $12 \mathrm{a}){ }^{239}$

$\mathbf{a}$

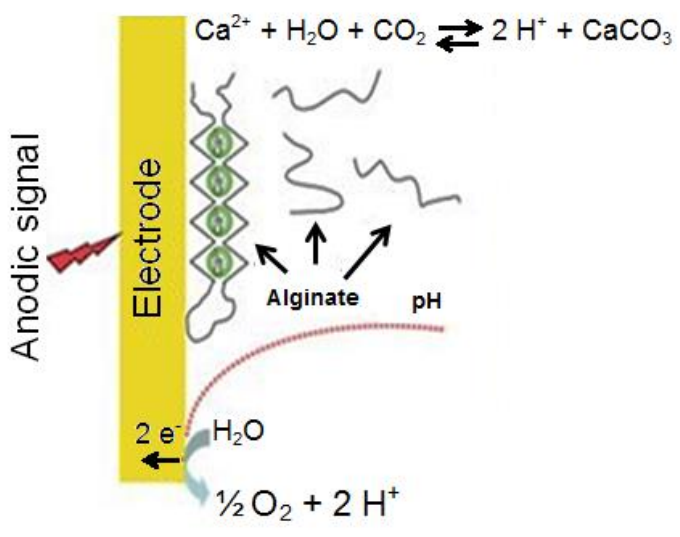

b

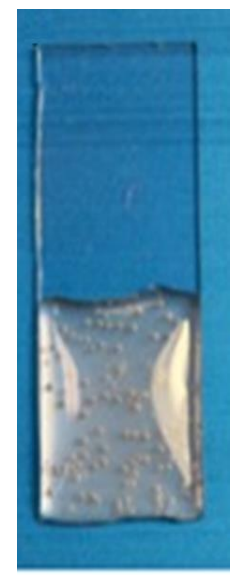

Figure 12. (a) Mechanism of calcium alginate electro-self-assembly. (b) Electro-self-assembled calcium alginate gel on an ITO-coated glass slide for $5 \mathrm{~min}$ at a current density of $3 \mathrm{~A} / \mathrm{m}^{2}$. Reproduced with permission from reference 239. Copyright 2009 John Wiley and Sons.

Generated in a mixed solution of alginate and insoluble calcium carbonate $\left(\mathrm{CaCO}_{3}\right)$ microparticles, protons partially dissolve $\mathrm{CaCO}_{3}$ releasing free calcium ions which interact with alginate to form a gel on the surface of the electrode. ${ }^{240}$ Figure $12 \mathrm{~b}$ shows an electro-self-assembly calcium alginate 
gel with a thickness of $6 \mu \mathrm{m}$ whose opacity is due to entrapped $\mathrm{CaCO}_{3}$ particles. The thickness can be tuned simply by changing the buildup time and the current density. ${ }^{239-240}$ Spatial control of the alginate film self-assembly was obtained using patterned electrodes (Figure 13). Confined 3D hydrogels, with a defined shape, were obtained by using an insulating paper with a hole (500 $\mu \mathrm{m}$ in diameter) localized on the working electrode. ${ }^{241} \mathrm{In} 2013, \mathrm{CaCO}_{3}$ particles free alginate gels were developed using electrochemistry. ${ }^{242} \mathrm{~A}$ first layer of electro-self-assembled alginate $/ \mathrm{CaCO}_{3}$ gel, used as a reservoir of calcium ions, was put into contact with a calcium free alginate solution during the application of a constant potential to form a second layer of alginate gel. Another electrochemical process was described allowing the self-assembly of alginate films based on ionic interactions with iron. Alginate/Fe(III) based thin films were obtained by oxidation of $\mathrm{Fe}$ (II) ions (at $0.8 \mathrm{~V}$ vs $\mathrm{Ag} / \mathrm{AgCl}$ ) in the presence of soluble alginate. ${ }^{243}$ The deposited thin film could be dissolved upon reduction voltage $(-0.4 \mathrm{~V})$ allowing the release of encapsulated proteins. This property is interesting for the development of electrochemically triggered drug release systems. By applying anodic conditions (typically $0.63 \mathrm{~V}$ vs SCE) at a chromium working electrode to generate protons, $\mathrm{PAH}$ and molybdate ion $\left(\mathrm{MoO}_{4}{ }^{2-}\right)$ films were deposited due to $\mathrm{PAH}$ protonation and further ion complexation of the polycation. ${ }^{244}$ 
a

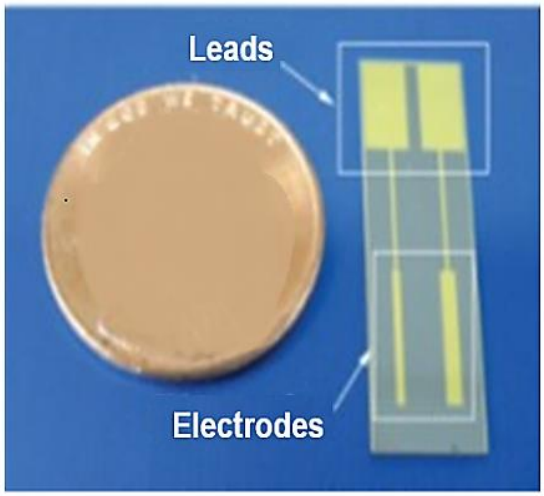

b

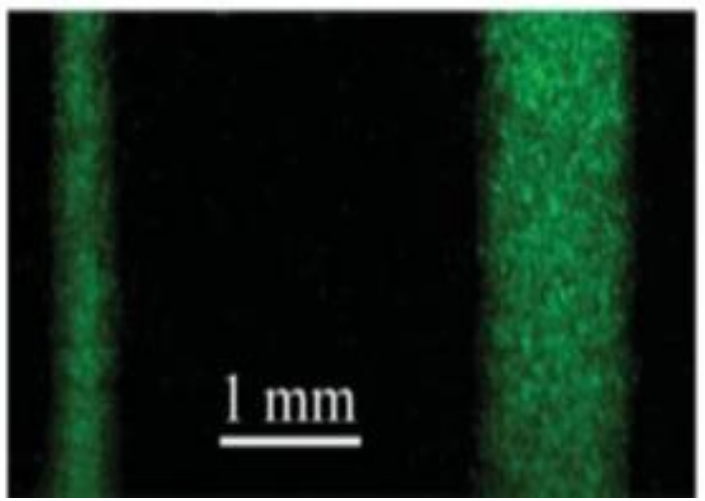

Figure 13. Spatial selectivity of calcium alginate electro-self-assembly on a patterned chip. a) The chip is a silicon wafer with two patterned gold electrodes. b) Fluorescence photomicrograph of electro-self-assembled calcium alginate gels with entrapped fluorescent microparticles. Reproduced with permission from reference 239. Copyright 2009 John Wiley and Sons.

Applications. Going further, calcium alginate gels can be co-deposited with cells or bacteria on patterned surfaces in microfluidic devices, allowing in-time visualization of the film growth. ${ }^{245-246}$ Different types of bacteria or cells can be entrapped in electro-self-assembled calcium alginate gels, simultaneously or in a step-by-step manner and remain viable. ${ }^{239,246-247}$ By using patterned ITO electrodes, Matsue et al. obtained cell-spheroids cultures in alginate gel microwells. ${ }^{247}$ It should be noted that vascular-like structures were developed by co-deposition of alginate calcium and cells on a platinum wire electrode. ${ }^{248}$ This method of encapsulation allows to develop model bacterial biofilms to study cell signaling ${ }^{246}$ or immunoanalysis. ${ }^{249}$ Alginate was also co-deposited with hemoglobin onto a porous Co-Ni film to obtain drug delivery platforms. ${ }^{250}$ Very recently, magnetically labeled cells were encapsulated in electrodeposited alginate gel. 3D organized assemblies of cells were obtained by coupling with a magnetic field (Figure 14). ${ }^{251}$ In a first step, the orientation of the magnetic field allows to arrange specifically the cells. In a second step, a patterned light illumination was projected onto the photoconductive substrate, serving as a photoanode, to electrodeposit the alginate gel, providing a suitable matrix for encapsulation of oriented 
cells on the electrode (Figure 14a-b). At the end of the light illumination, the introduction of fresh culture medium into the microchamber allowed to remove the residual deposition solution (Figure $14 \mathrm{c})$.

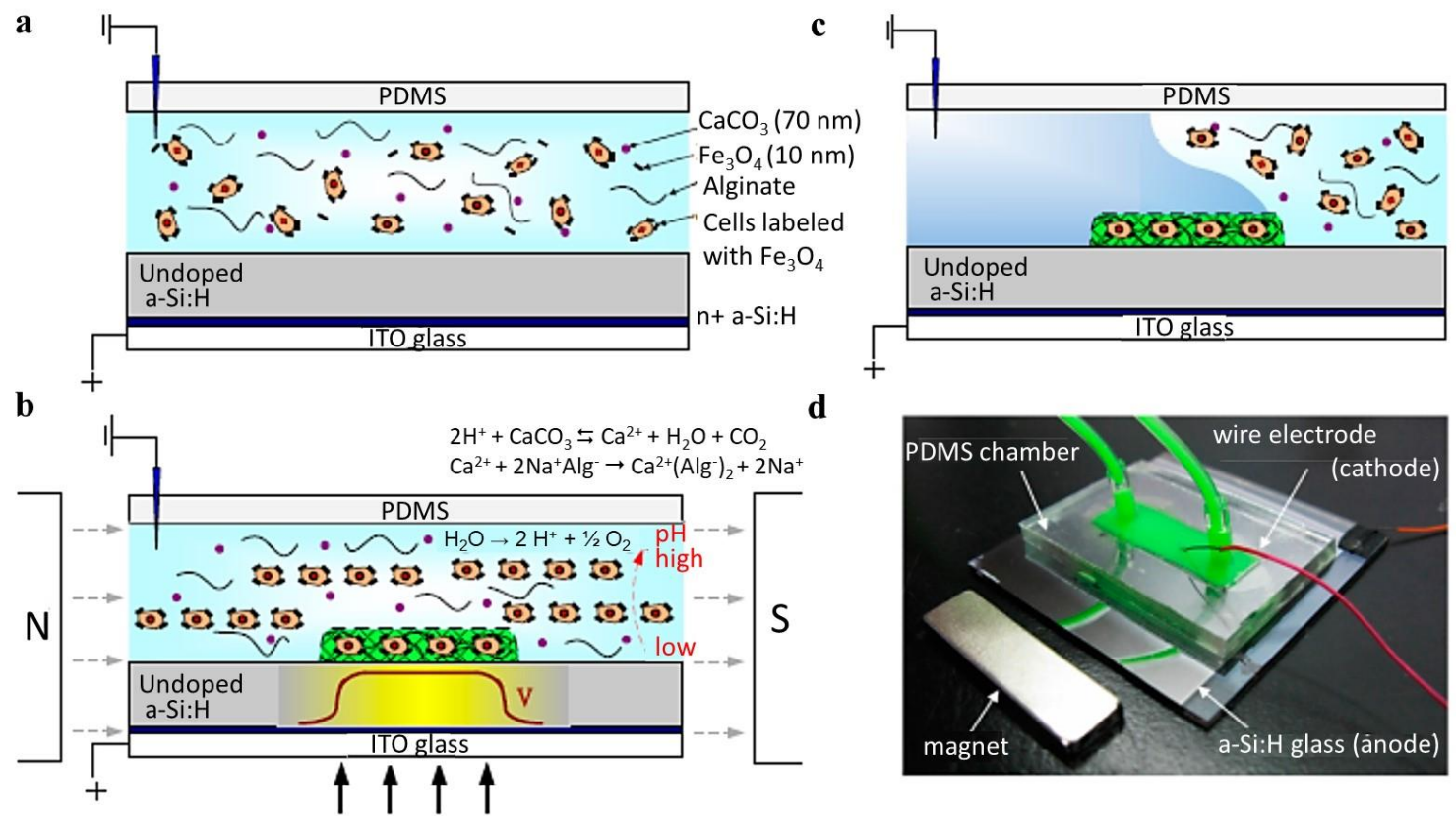

Figure 14. $(\mathrm{a}-\mathrm{c})$ Schematic diagrams of a light-addressable electrolytic system used to perform an electrodeposition of magnetically-guided cells encapsulated in alginate hydrogels using a digital micromirror device (DMD). (d) Image of the polydimethylsiloxane (PDMS) microchamber bonded to the photoconductive substrate with a metallic wire inserted into the microchamber as the cathode (green dye was introduced into the microchamber for visibility purposes). Reproduced from reference 251. Open Access 2014 MDPI

3. Electrochemical deposition through covalent bond formation

3.1 Electropolymerization 
Since 1980's, electropolymerization provides a major route for the synthesis of conducting polymers. Electropolymerization employs electrochemical oxidation of monomers, creating reactive radicals which polymerize and generate an insoluble polymer film. This kind of reaction is limited to monomers that can undergo an oxidation to form a radical. Electropolymerization has been widely used to design enzymatic biosensors ${ }^{252-254}$ and biofuel cells. ${ }^{201}$ Most electropolymerized films used for biomolecule immobilization are conducting polymers. Indeed, enzyme molecules that are present in the immediate vicinity of the electrode surface can be physically incorporated within the growing polymer network. Electrochemical deposition of enzymes was coupled with electropolymerization to physically entrap enzymes in a conductive matrix. ${ }^{255}$ This was done with polyaniline, ${ }^{256}$ polypyrrole, ${ }^{257-259}$ poly $(3,4-$ ethylenedioxythiophene), ${ }^{199}$ poly-o-aminophenol, ${ }^{196,} \quad 260$ or $\quad$ poly(o-phenylenediamine $) .{ }^{261}$ Electropolymerisation is intensively applied for the buildup of molecularly imprinted polymers used for non-enzymatic protein recognition. The concept is based on the polymerization of suitable functional monomers (conductive or not) in the presence of a target protein acting as a template. The subsequent removal of the template creates recognition sites that can, further on, selectively rebind the target such as human serum albumin, ${ }^{262}$ myoglobin ${ }^{263}$ or hexameric heme protein. ${ }^{264}$ Electropolymerization is a field in itself and will not be discussed in further details here as it was already done in several excellent reviews. ${ }^{265-269}$

\subsection{Electrochemical-coupling layer-by-layer}

ElectroChemical-Coupling Layer-by-Layer (ECC-LbL) consists in an enhanced version of LbL assembly, where an electrotriggered cross-linking of the polymer layers is added between each deposition step. In 2010, we introduced the first example based on two polyelectrolytes bearing alkyne or azide functions able to cross-link through $\mathrm{Cu}(\mathrm{I})$ catalyzed Sharpless-Huisgens click 
reaction. ${ }^{270}$ At each adsorption step of alkyne-modified polymer and azide-modified polymer, a reductive potential $(-0.35 \mathrm{~V}$ vs $\mathrm{Ag} / \mathrm{AgCl})$ was applied in the presence of $\mathrm{Cu}(\mathrm{II})$ to generate a $\mathrm{Cu}(\mathrm{I})$ gradient at the electrode. The presence of $\mathrm{Cu}(\mathrm{I})$ triggers the click reaction between alkyne and azide moieties leading to covalent cross-linking of each layer. Using the designation "ECC-LbL" on a system based on the electrochemical triggering of $\mathrm{N}$-alkylcarbazole dimerization, ${ }^{271}$ Ariga and co-workers applied the concept to immobilize carbazole functionalized porphyrin, fullerene and fluorine (Figure 15)..$^{272}$


Figure 15. Molecules used for electrochemical-coupling layer-by-layer (ECC-LbL) assembly through cross-linking of peripheral N-alkylcarbazole units. Reproduced with permission from reference 272. Copyright 2011 American Chemical Society.

Photovoltaic functions of a prototype $\mathrm{p} / \mathrm{n}$ hetero-junction device were demonstrated by the alternate deposition of donor (porphyrin) and acceptor (fullerene) molecules. As for other electrochemically triggered systems, ECC-LbL can be performed on patterned electrodes for spatial control of the assembly. ${ }^{273}$ Allowing the control of gold nanoparticle distribution in LbL, ECC-LbL offers an economical route to achieve the fabrication of both a gold electrode and a photoactive carbazole rich layer. ${ }^{274}$ 
3.3 Electro-crosslinking of polymers: one pot morphogen self-construction of films

In 2011, our group went one step further and introduced the concept of "one-pot morphogen driven self-assembly". ${ }^{275}$ In analogy with developmental biological processes, ${ }^{276}$ a morphogen is defined as a molecule or an ion that is produced at an interface and diffuses into the solution, thus creating a concentration gradient, and that locally induces a chemical process. Electrotriggered $\mathrm{Cu}^{\mathrm{I}-}$ catalyzed click reaction between azide and alkyne functionalized polymers was used to illustrate the concept which is schematically represented in Figure 16a-b. ${ }^{277}$

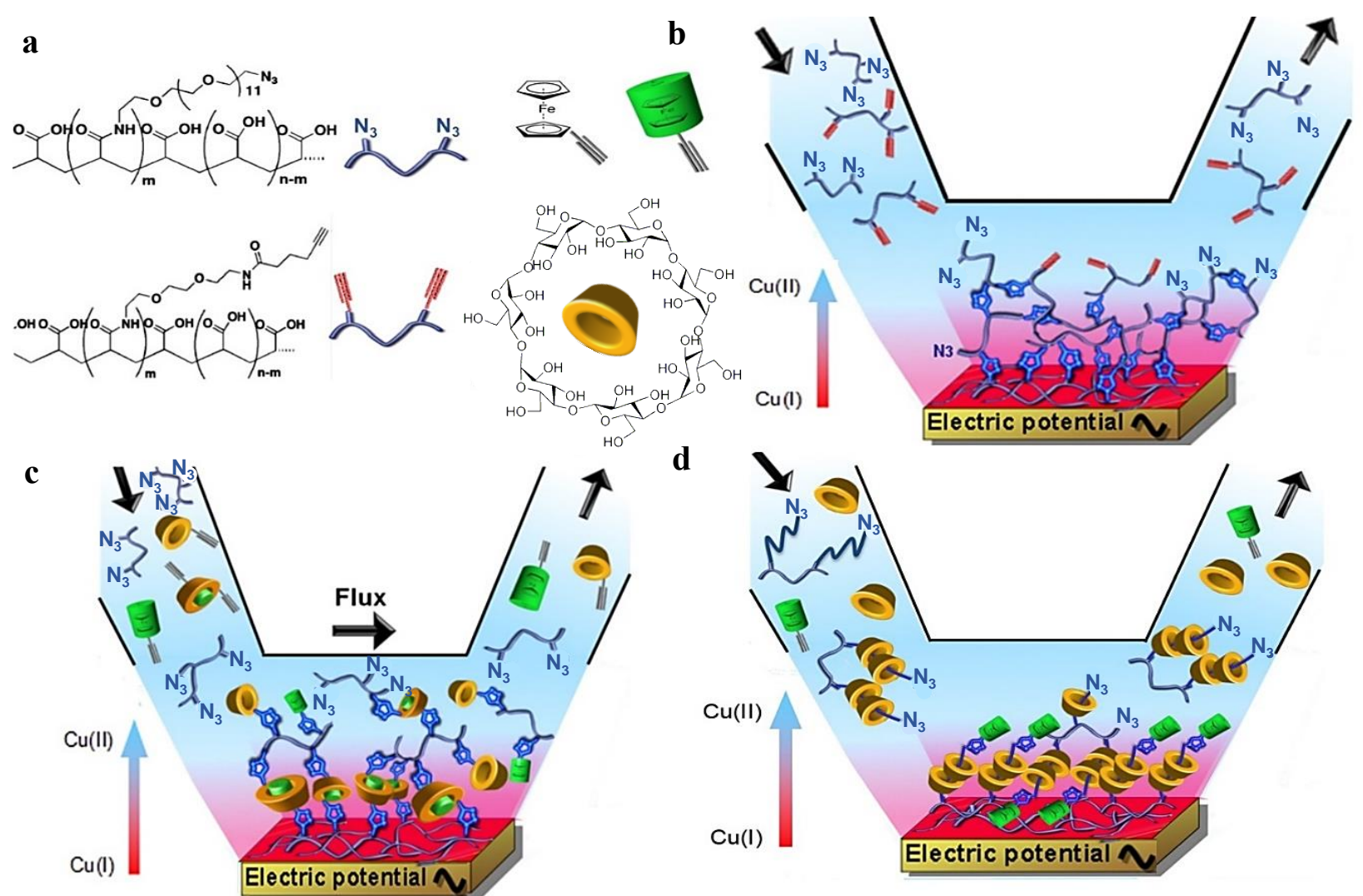

Figure 16. One pot morphogen electrochemically driven self-construction of different films by click-chemistry: (a) chemical formulae of the different compounds, (b) PAA-based covalent films, Reproduced with permission from reference 278. Copyright 2011 Elsevier. PAA-ferrocene$\beta$-cyclodextrin films based on (c) host-guest interactions and (d) polyrotaxanes. Clickable PAA 
(PAA-N ${ }_{3}$, PAA-C $\equiv C$ ), ethynyl-ferrocene and ethynyl- $\beta-$ cyclodextrin- $\mathrm{C} \equiv \mathrm{C}$ react together in the presence of a $\mathrm{Cu}(\mathrm{I})$ gradient electrochemically generated from $\mathrm{Cu}(\mathrm{II})$ by application of a cyclic voltammetry $(\mathrm{CV})$ at the working electrode.

Two chemically modified poly(acrylic acid), one bearing azide (PAA-N ${ }_{3}$ ) and one bearing alkyne (PAA-C $\equiv C$ ) functions, were mixed in solution in the presence of $\mathrm{Cu}(\mathrm{II})$. These polymers are unable to interact one with each other under these conditions. When an electric potential (cyclic voltammetry from $-0.35 \mathrm{~V}$ to $0.5 \mathrm{~V}$ vs $\mathrm{Ag} / \mathrm{AgCl}$ ) was applied, $\mathrm{Cu}$ (II) was reduced generating a $\mathrm{Cu}(\mathrm{I})$ gradient which catalyzed the reaction between azide and alkyne functions of the two polymers. $\mathrm{Cu}(\mathrm{I})$ was called a morphogen in analogy with biochemical species that diffuse in tissues and modify cell fate. ${ }^{9}{ }^{276}$ This process leads to the assembly of an electrocrosslinked polymeric film on the electrode surface. Based on the same morphogen and the same reaction, we also generated, in a one-pot manner, films composed of alkyne-grafted polymers and short azidemodified bifunctional ethylene glycol. ${ }^{279}$ By using different sizes of homobifunctional ethylene glycol spacers, the thickness and the morphology of the self-assembled films could be tuned. Different types of azide and alkyne functionalized polymers ${ }^{275}$ can also be used, among them chitosan to develop antimicrobial coatings. ${ }^{280}$ Films based on host-guest interactions were built using a (PAA-N $\mathrm{N}_{3}$, ethynyl-ferrocene, ethynyl- $\beta$-cyclodextrin- $\mathrm{C} \equiv \mathrm{C}$ ) mixture (Figure $\left.16 \mathrm{c}\right) .{ }^{281}$ The obtained films allow the further trapping of hydrophobic molecules in free $\beta$-cyclodextrin moieties present in the film. Using the same process, coatings based on supramolecular polyrotaxane were obtained from a (PAA- $\mathrm{N}_{3}$, ethynyl-ferrocene, $\beta($ or $\alpha$ )-cyclodextrin) mixture using electroclick to lock the polyrotaxane geometry (Figure 16d). ${ }^{282}$ One step elaboration of inorganic coatings was achieved by applying the electroclick morphogen driven self-construction concept to azide and alkyne functionalized nanoparticles (NPs). The electrodeposition of clickable 
iron oxide NPs allows the selective filling of high aspect ratio nanodevices establishing an electrical connection between two gold electrodes separated by a $100 \mathrm{~nm}$-wide nanotrench (Figure 17). ${ }^{283}$
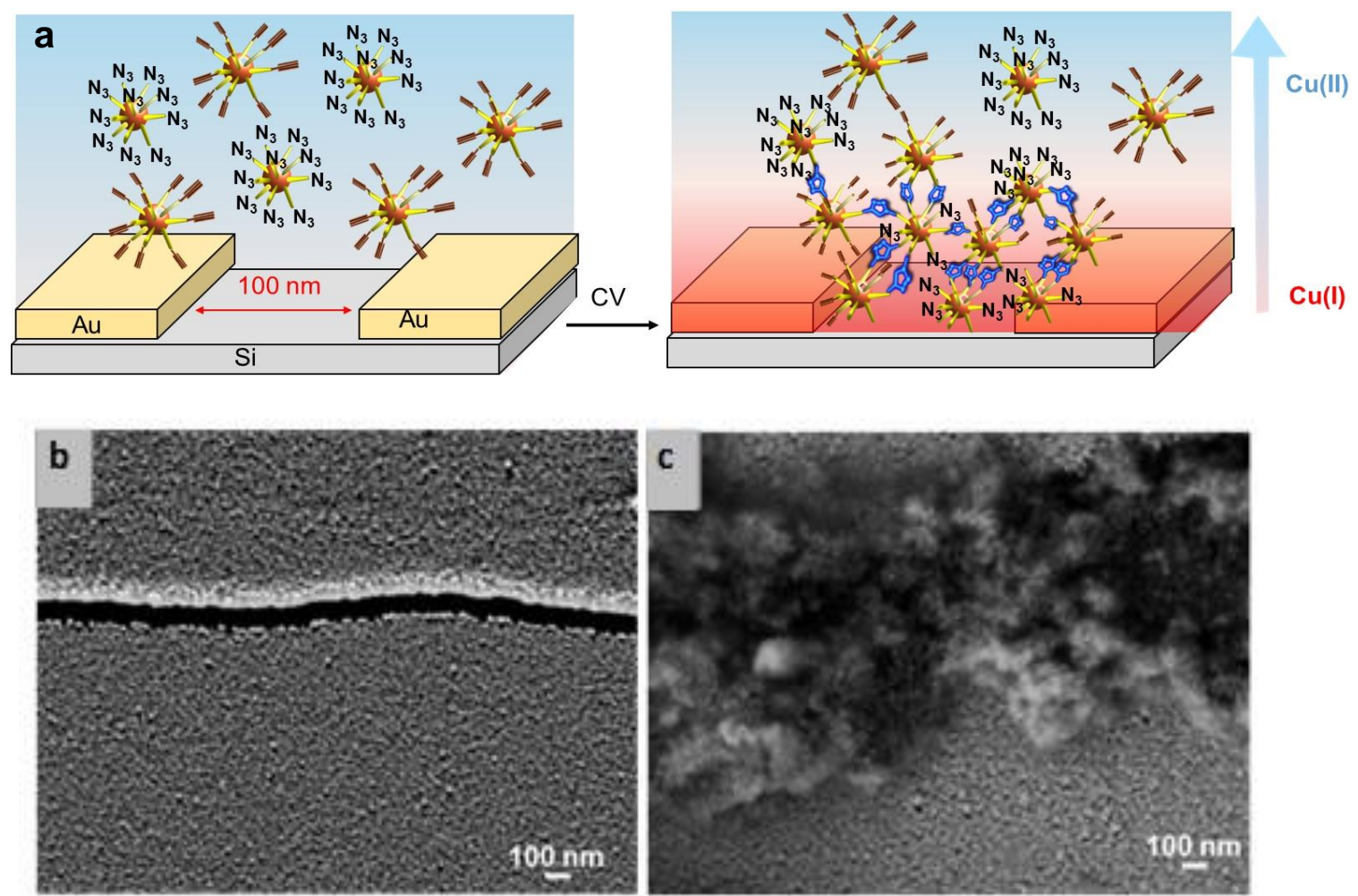

Figure 17. One-pot electro-click self-construction of NP films for selective filling of nanotrenches.

(a) Schematic representation of the process using alkyne and azide functionalized iron oxide NPs.

SEM micrographs of a $100 \mathrm{~nm}$-wide nanotrench (b) before and (c) after filling by iron oxide NPs (20 $\mathrm{nm}$ in diameter) after $120 \mathrm{~min}$ of CV. Reproduced with permission from reference 283. Copyright 2015 John Wiley and Sons.

Integration of covalent NP films into nanodevices opens the route for biosensing and granular electronic devices. Simultaneous electropolymerization and electroclick functionalization (SEEC) of poly(aniline) was developed using clickable aniline monomers by application of a cyclic 
voltammetry $(-0.6 \mathrm{~V}$ to $+0.9 \mathrm{~V}$ vs $\mathrm{Ag} / \mathrm{AgCl}){ }^{284}$ This process allows the control of the film morphology and activity by changing the electropolymerization condition and the electroclicked molecules, respectively.

In 2012 by application of an anodic current, Gray et al. generated chlorine species (HOCl) to partially oxidize chitosan forming aldehydes that could further react with amine moieties of the polymer. As the $\mathrm{HOCl}$ is generated at the surface of the electrode, the conjugation reaction is localized at the electrode inducing the formation of a biopolymeric hydrogel. ${ }^{285} \mathrm{Co}$-deposition of chitosan with $\mathrm{GOX}^{285}$ or glucose dehydrogenase ${ }^{286}$ allows obtaining $\mathrm{pH}$-stable chemical gels with simultaneously conjugating a protein. Very recently, we introduced the electro-crosslinking of polyamines based on mussel-inspired chemistry (Figure 18) ${ }^{287}$ Mussels presents unusual adhesion properties under extreme conditions on almost any kind of materials. This ability comes from the secretion of different proteins rich in catechol moieties which have several chemical properties. ${ }^{288-}$ ${ }^{289}$ Among them, catechol functions can be oxidized into quinone functions able to react with nucleophilic groups, such as amines or thiols. Using this property, we developed a catechol based electrochemically triggered construction of polymeric films. The principle is based on the application of defined potential cycles on an electrode in contact with a mixture of PAH and biscatechol spacers, both unable to interact (Figure 18a). During the application of the potential, catechols are oxidized into quinones which then crosslink the polymer chains by reacting with the amine functions through Michael addition and Schiff's base formation (Figure 18b). The buildup kinetic can be tuned by the catechol/amine ratio of PAH/bis-catechol mixture and the scan rate of the CV. This work open the route for biosensing application. Indeed, enzymes could be immobilized trough covalent bonds with this process without any previous functionalization of the protein. 
a

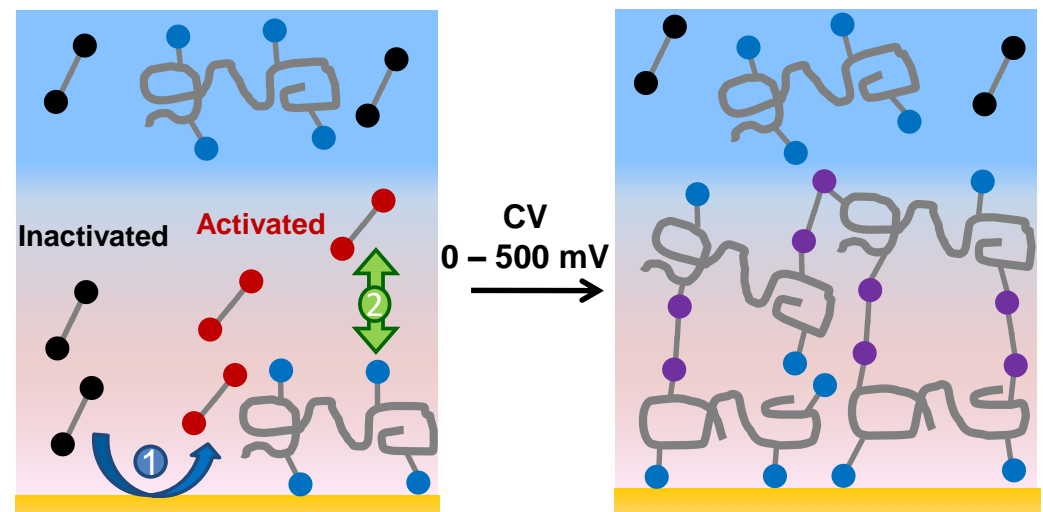

Gold electrode

Gold electrode

b

Step 1: electrochemical oxydation of bis-catechol

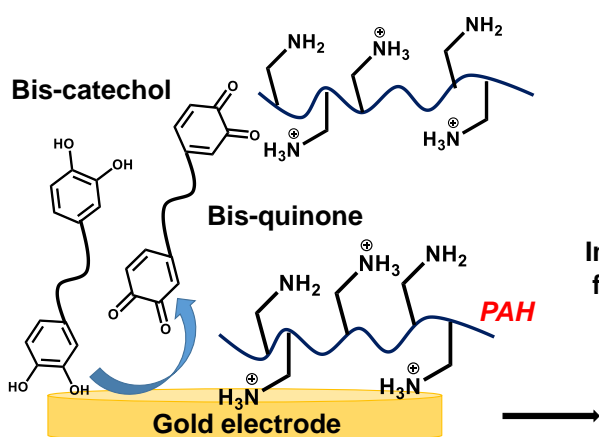

Step 2: covalent crosslinking between PAH and bis-catechol



Figure 18. (a) Principle of the one pot self-construction of polymeric film based on oxidation of an organic morphogen and (b) schematic representation of the two chemical steps leading to covalent crosslinking between PAH and catechol homobifunctionalized ethylene glycol spacer, named bis-catechol. Reproduced with permission from reference 287. Copyright 2015 American Chemical Society.

\section{CONCLUSION AND PERSPECTIVES}

Different macromolecular film buildup processes triggered by electrochemistry are reviewed. A large variety of such processes exists based on different physico-chemical grounds: precipitation, 
polymerization or cross-linking (ionic or covalent). Performed in aqueous solution, a large number of electrodeposition processes are based on the generation of chemical species, which can be called morphogens, at the electrode that then diffuse towards the solution, inducing the film buildup. In general, the different processes are triggered with potentials lying between -2 to $1.5 \mathrm{~V}$ (rarely up to $30 \mathrm{~V}$ or $\mathrm{kV}$ ) and current intensity about few $\mathrm{A} / \mathrm{m}^{2}$. Thin functionalized films or thick hydrogels are obtained by electroprecipitation of macromolecules to implement enzymatic and nonenzymatic biosensors which need a further crosslinking step to ensure their operating stability. Ionic self-assembly of macromolecules, especially alginate, allows the encapsulation of cells in a suitable environment in mild conditions. Finally, robust functionalized thin films can be designed through covalent cross-linking of macromolecules or inorganic compounds.

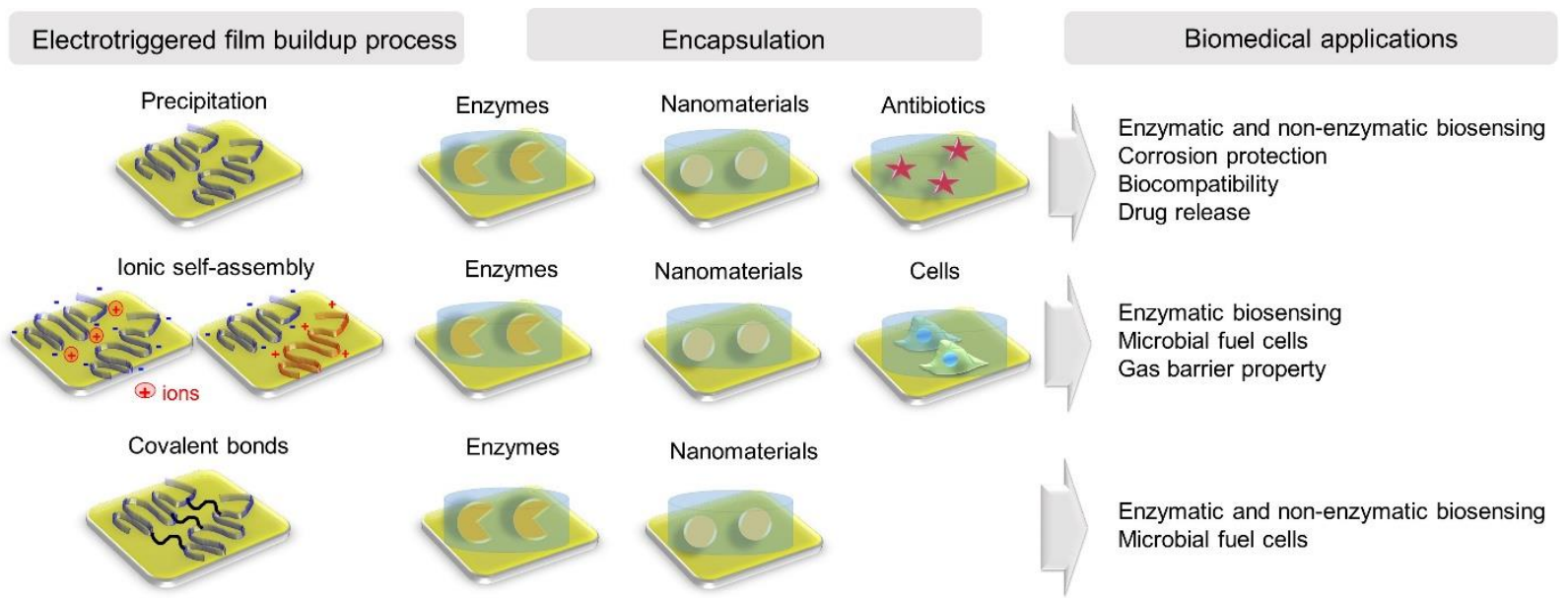

Figure 19. Summary of the different reviewed electrotriggered film buildup processes and their biomedical applications.

First developed to coat metals in the car industry, electrochemically triggered self-assembly processes are gaining new interests. Their great advantage is to allow the localized deposition of different macromolecules, molecules or inorganic compounds on micro-electrodes. Moreover as the process is controlled by an electrochemical stimulus (current or potential), the trigger can be 
switched "on" and "off" allowing the buildup of structured multilayered coatings by finely controlling the application time of the stimulus and by alternating the application of reductive and oxidative potential. ${ }^{290}$ Among the reviewed macromolecular film buildup processes, very few are based on coordination bonds. Coordination chemistry, especially metal-ligand, has several advantages due to highly directional interactions, exchangeable components and a multivalent nature. ${ }^{291}$ The development of new process which incorporate metal-ions into a supramolecular architecture will give access to rich properties with potential applications for magnetic, electric and optical devices. ${ }^{292}$ For example, Metal-Organic Frameworks (MOFs) are a class of materials designed by employing various metal ions and organic linkers. Emerging as an extensive class of crystalline materials with high porosity in nature, MOFs have diverse applications like storage or separation of gases, catalysis, magnetism, luminescence and drug storage and delivery. ${ }^{292-293}$ As another perspective using two micro-electrodes, the electrogeneration of two morphogens will allow designing structured coatings at the overlap of two gradients opening the route of the functionalization of non-conductive substrates. Finally, an even further step is to generate the morphogens using adsorbed enzymes which would allow extending the localized buildup processes to non-conductive surfaces with no use of an electrochemical stimulus.

\section{AUTHOR INFORMATION}

\section{Corresponding Author}

*fouzia.boulmedais@ics-cnrs.unistra.fr

\section{Author Contributions}

The manuscript was written through contributions of all authors. All authors have given approval to the final version of the manuscript. 


\section{ACKNOWLEDGMENT}

C.M. was supported by a fellowship from the "Ministère de la Recherche et de la Technologie".

The authors gratefully acknowledge financial support from Agence Nationale de la Recherche (ANR JCJC Morphobuildup, ANR-13-JS08-0003-01), Labex “Chimie des Systèmes Complexes" (Labex CSC), International Center for Frontier Research in Chemistry (icFRC) and University of Strasbourg Institute for Advanced Study (USIAS).

\section{REFERENCES}

(1) Khelifa, F.; Ershov, S.; Habibi, Y.; Snyders, R.; Dubois, P. Free-Radical-Induced Grafting from Plasma Polymer Surfaces. Chem. Rev. 2016, 116, 3975-4005.

(2) Matsuoka, H.; Mizutani, S.; Watanabe, C.; Yamauchi, S. High-Frequency Epr Studies on Polymer Chain Morphology in Dip-Coated Films of Poly(3-Hexylthiophene)/Fullerene BulkHeterojunctions. Bull. Chem. Soc. Jpn. 2016, 89, 378-384.

(3) Schottler, S.; Becker, G.; Winzen, S.; Steinbach, T.; Mohr, K.; Landfester, K.; Mailander, V.; Wurm, F. R. Protein Adsorption Is Required for Stealth Effect of Poly(Ethylene Glycol)- and Poly(Phosphoester)-Coated Nanocarriers. Nat Nanotechnol 2016, 11, 372-377.

(4) Blodgett, K. B.; Langmuir, I. Buildup Films of Barium Stearate and Their Optical Properties. Phys. Rev. 1937, 51, 964-982.

(5) Ariga, K.; Yamauchi, Y.; Mori, T.; Hill, J. P. 25th Anniversary Article: What Can Be Done with the Langmuir-Blodgett Method? Recent Developments and Its Critical Role in Materials Science. Adv. Mater. 2013, 25, 6477-6512.

(6) Decher, G. Fuzzy Nanoassemblies: Toward Layered Polymeric Multicomposites. Science 1997, 277, 1232-1237.

(7) Rydzek, G.; Schaaf, P.; Voegel, J. C.; Jierry, L.; Boulmedais, F. Strategies for Covalently Reticulated Polymer Multilayers. Soft Matter 2012, 8, 9738-9755.

(8) Richardson, J. J.; Cui, J. W.; Bjornmalm, M.; Braunger, J. A.; Ejima, H.; Caruso, F. Innovation in Layer-by-Layer Assembly. Chem. Rev. 2016, 116, 14828-14867.

(9) Turing, A. M. The Chemical Basis of Morphogenesis. Philos. Trans. R. S. London 1952, 327, 37.

(10) Sheppard, S. E.; Eberlin, L. W. Process of Electrodepositing Rubber Upon a Metal Wire. US Patent 1,589,329, Nov 20, 1926.

(11) Sumner, C. G.; Johnson, R. I.; Clayton, W. Process of Protecting Metal Surfaces by Electrodeposition. US Patent 2,215,167, Sept 17, 1940.

(12) Sheppard, S. E.; Beal, C. L. Electrodeposition of Organic Material US Patent 1,855,809, April 5, 1932.

(13) Brewer, G. E. F. Electrophoretic Painting. J. Appl. Electrochem. 1983, 13, 269-275.

(14) Niemann, J. Waterborne Coatings for the Automotive Industry. Prog. Org. Coat. 1992, 21, 189-203. 
(15) Beck, F. Fundamental Aspects of Electrodeposition of Paint. Prog. Org. Coat. 1976, 4, 160.

(16) Krylova, I. A.; Zubov, P. I. Formation and Properties of Coatings Produced by Electrodeposition of Paints. Prog. Org. Coat. 1984, 12, 129-141.

(17) Beck, F. Electrodeposition of Polymer-Coatings. Electrochim. Acta 1988, 33, 839-850.

(18) Krylova, I. Painting by Electrodeposition on the Eve of the 21st Century. Prog. Org. Coat. 2001, 42, 119-131.

(19) Furuno, N.; Kawai, H.; Oyabu, Y. Mechanism of Film Formation by the Electrodeposition Coating. J. Colloid Interface Sci. 1975, 55, 297-304.

(20) Bieganska, B.; Zubielewicz, M.; Smieszek, E. Anticorrosive Water-Borne Paints. Prog. Org. Coat. 1987, 15, 33-56.

(21) Schenck, H. U.; Spoor, H.; Marx, M. Chemistry of Binders for Electrodeposition. Prog. Org. Coat. 1979, 7, 1-77.

(22) Wu, L. Q.; Gadre, A. P.; Yi, H. M.; Kastantin, M. J.; Rubloff, G. W.; Bentley, W. E.; Payne, G. F.; Ghodssi, R. Voltage-Dependent Assembly of the Polysaccharide Chitosan onto an Electrode Surface. Langmuir 2002, 18, 8620-8625.

(23) Rinaudo, M.; Pavlov, G.; Desbrieres, J. Influence of Acetic Acid Concentration on the Solubilization of Chitosan. Polymer 1999, 40, 7029-7032.

(24) Sorlier, P.; Denuziere, A.; Viton, C.; Domard, A. Relation between the Degree of Acetylation and the Electrostatic Properties of Chitin and Chitosan. Biomacromolecules 2001, 2, 765-772.

(25) Simchi, A.; Pishbin, F.; Boccaccini, A. R. Electrophoretic Deposition of Chitosan. Mater. Lett. 2009, 63, 2253-2256.

(26) Cheng, Y.; Luo, X. L.; Betz, J.; Buckhout-White, S.; Bekdash, O.; Payne, G. F.; Bentley, W. E.; Rubloff, G. W. In Situ Quantitative Visualization and Characterization of Chitosan Electrodeposition with Paired Sidewall Electrodes. Soft Matter 2010, 6, 3177-3183. (27) Cheng, Y.; Gray, K. M.; David, L.; Royaud, I.; Payne, G. F.; Rubloff, G. W. Characterization of the Cathodic Electrodeposition of Semicrystalline Chitosan Hydrogel. Mater. Lett. 2012, 87, 97-100.

(28) Zangmeister, R. A.; Park, J. J.; Rubloff, G. W.; Tarlov, M. J. Electrochemical Study of Chitosan Films Deposited from Solution at Reducing Potentials. Electrochim. Acta 2006, 51, 5324-5333.

(29) Fernandes, R.; Wu, L. Q.; Chen, T. H.; Yi, H. M.; Rubloff, G. W.; Ghodssi, R.; Bentley, W. E.; Payne, G. F. Electrochemically Induced Deposition of a Polysaccharide Hydrogel onto a Patterned Surface. Langmuir 2003, 19, 4058-4062.

(30) Altomare, L.; Draghi, L.; Chiesa, R.; De Nardo, L. Morphology Tuning of Chitosan Films Via Electrochemical Deposition. Mater. Lett. 2012, 78, 18-21.

(31) Liu, Y.; Zhang, B.; Gray, K. M.; Cheng, Y.; Kim, E.; Rubloff, G. W.; Bentley, W. E.; Wang, Q.; Payne, G. F. Electrodeposition of a Weak Polyelectrolyte Hydrogel: Remarkable Effects of Salt on Kinetics, Structure and Properties. Soft Matter 2013, 9, 2703-2710.

(32) Yan, K.; Ding, F. Y.; Bentley, W. E.; Deng, H. B.; Du, Y. M.; Payne, G. F.; Shi, X. W. Coding for Hydrogel Organization through Signal Guided Self-Assembly. Soft Matter 2014, 10, 465-469.

(33) Buckhout-White, S. L.; Rubloff, G. W. Spatial Resolution in Chitosan-Based Programmable Biomolecular Scaffolds. Soft Matter 2009, 5, 3677-3681. 
(34) Wu, L. Q.; Yi, H. M.; Li, S.; Rubloff, G. W.; Bentley, W. E.; Ghodssi, R.; Payne, G. F. Spatially Selective Deposition of a Reactive Polysaccharide Layer onto a Patterned Template. Langmuir 2003, 19, 519-524.

(35) Wei, X. Q.; Payne, G. F.; Shi, X. W.; Du, Y. M. Electrodeposition of a Biopolymeric Hydrogel in Track-Etched Micropores. Soft Matter 2013, 9, 2131-2135.

(36) Huang, S. H.; Wei, L. S.; Chu, H. T.; Jiang, Y. L. Light-Addressed Electrodeposition of Enzyme-Entrapped Chitosan Membranes for Multiplexed Enzyme-Based Bioassays Using a Digital Micromirror Device. Sensors 2013, 13, 10711-10724.

(37) Cheong, M.; Zhitomirsky, I. Electrodeposition of Alginic Acid and Composite Films. Colloids Surf., A 2008, 328, 73-78.

(38) Ma, R.; Epand, R. F.; Zhitomirsky, I. Electrodeposition of Hyaluronic Acid and Hyaluronic Acid-Bovine Serum Albumin Films from Aqueous Solutions. Colloids Surf., B 2010, 77, 279285.

(39) Wang, Y.; Pang, X.; Zhitomirsky, I. Electrophoretic Deposition of Chiral Polymers and Composites. Colloids Surf., B 2011, 87, 505-509.

(40) Wu, K. M.; Imin, P.; Sun, Y. C.; Pang, X.; Adronov, A.; Zhitomirsky, I. Electrophoretic Deposition of Composite Films from Solutions of Conjugated Polymers and Their Supramolecular Complexes with Carbon Nanotubes. Mater. Lett. 2012, 67, 248-251.

(41) Casagrande, T.; Imin, P.; Cheng, F. Y.; Botton, G. A.; Zhitomirsky, I.; Adronov, A. Synthesis and Electrophoretic Deposition of Single-Walled Carbon Nanotube Complexes with a Conjugated Polyelectrolyte. Chem. Mater. 2010, 22, 2741-2749.

(42) Wang, Y.; Deen, I.; Zhitomirsky, I. Electrophoretic Deposition of Polyacrylic Acid and Composite Films Containing Nanotubes and Oxide Particles. J. Colloid Interface Sci. 2011, 362, 367-374.

(43) Kurzawa, C.; Hengstenberg, A.; Schuhmann, W. Immobilization Method for the Preparation of Biosensors Based on Ph Shift-Induced Deposition of Biomolecule-Containing Polymer Films. Anal. Chem. 2002, 74, 355-361.

(44) Reddy, K. R. C.; Turcu, F.; Schulte, A.; Kayastha, A. M.; Schuhmann, W. Fabrication of a Potentiometric/Amperometric Bifunctional Enzyme Microbiosensor. Anal. Chem. 2005, 77, 5063-5067.

(45) Isik, S.; Oni, J.; Rjabova, V.; Neugebauer, S.; Schuhmann, W. Entrapment of Metalloporphyrins within an Electrodeposition Paint Layer as a Basis for Developing a Nitric Oxide Sensor. Microchim. Acta 2004, 148, 59-64.

(46) Ngounou, B.; Neugebauer, S.; Frodl, A.; Reiter, S.; Schuhmann, W. Combinatorial Synthesis of a Library of Acrylic Acid-Based Polymers and Their Evaluation as Immobilisation Matrix for Amperometric Biosensors. Electrochim. Acta 2004, 49, 3855-3863.

(47) Szamocki, R.; Velichko, A.; Muecklich, F.; Reculusa, S.; Ravaine, S.; Neugebauer, S.; Schuhmann, W.; Hempelmann, R.; Kuhn, A. Improved Enzyme Immobilization for Enhanced Bioelectrocatalytic Activity of Porous Electrodes. Electrochem. Commun. 2007, 9, 2121-2127. (48) Vilkanauskyte, A.; Erichsen, T.; Marcinkeviciene, L.; Laurinavicius, V.; Schuhmann, W. Reagentless Biosensors Based on Co-Entrapment of a Soluble Redox Polymer and an Enzyme within an Electrochemically Deposited Polymer Film. Biosens. Bioelectron. 2002, 17, 10251031.

(49) Reiter, S.; Ruhlig, D.; Ngounou, B.; Neugebauer, S.; Janiak, S.; Vilkanauskyte, A.; Erichsen, T.; Schuhmann, W. An Electrochemical Robotic System for the Optimization of 
Amperometric Glucose Biosensors Based on a Library of Cathodic Electrodeposition Paints. Macromol. Rapid Commun. 2004, 25, 348-354.

(50) Ngounou, B.; Aliyev, E. H.; Guschin, D. A.; Sultanov, Y. M.; Efendiev, A. A.; Schuhmann, W. Parallel Synthesis of Libraries of Anodic and Cathodic Functionalized Electrodeposition Paints as Immobilization Matrix for Amperometric Biosensors. Bioelectrochemistry 2007, 71, 81-90.

(51) Guschin, D. A.; Shkil, H.; Schuhmann, W. Electrodeposition Polymers as Immobilization Matrices in Amperometric Biosensors: Improved Polymer Synthesis and Biosensor Fabrication. Anal. Bioanal. Chem. 2009, 395, 1693-1706.

(52) Alpeeva, I. S.; Vilkanauskyte, A.; Ngounou, B.; Csoregi, E.; Sakharov, I. Y.; Gonchar, M.; Schuhmann, W. Bi-Enzyme Alcohol Biosensors Based on Genetically Engineered Alcohol Oxidase and Different Peroxidases. Microchim. Acta 2005, 152, 21-27.

(53) Neugebauer, S.; Isik, S.; Schulte, A.; Schuhmann, W. Acrylic Acid-Based Copolymers as Immobilization Matrix for Amperometric Biosensors. Anal. Lett. 2003, 36, 2005-2020. (54) Neugebauer, S.; Stoica, L.; Guschin, D.; Schuhmann, W. Redox-Amplified Biosensors Based on Selective Modification of Nanopore Electrode Structures with Enzymes Entrapped within Electrodeposition Paints. Microchim. Acta 2008, 163, 33-40.

(55) Shkotova, L. V.; Soldatkin, A. P.; Gonchar, M. V.; Schuhmann, W.; Dzyadevych, S. V. Amperometric Biosensor for Ethanol Detection Based on Alcohol Oxidase Immobilised within Electrochemically Deposited Resydrol Film. Mater. Sci. Eng., C 2006, 26, 411-414.

(56) Smutok, O.; Ngounou, B.; Pavlishko, H.; Gayda, G.; Gonchar, M.; Schuhmann, W. A Reagentless Bienzyme Amperometric Biosensor Based on Alcohol Oxidase/Peroxidase and an Os-Complex Modified Electrodeposition Paint. Sens. Actuators, B 2006, 113, 590-598.

(57) Kueng, A.; Kranz, C.; Mizaikoff, B. Amperometric Atp Biosensor Based on Polymer Entrapped Enzymes. Biosens. Bioelectron. 2004, 19, 1301-1307.

(58) Guschin, D. A.; Castillo, J.; Dimcheva, N.; Schuhmann, W. Redox Electrodeposition Polymers: Adaptation of the Redox Potential of Polymer-Bound Os Complexes for Bioanalytical Applications. Anal. Bioanal. Chem. 2010, 398, 1661-1673.

(59) Poller, S.; Koster, D.; Schuhmann, W. Stabilizing Redox Polymer Films by

Electrochemically Induced Crosslinking. Electrochem. Commun. 2013, 34, 327-330.

(60) Hudak, N. S.; Gallaway, J. W.; Barton, S. C. Formation of Mediated Biocatalytic Cathodes by Electrodeposition of a Redox Polymer and Laccase. J. Electroanal. Chem. 2009, 629, 57-62.

(61) Chen, X. X.; Shao, M. L.; Poller, S.; Guschin, D.; Pinyou, P.; Schuhmann, W. Pqq-Sgdh Bioelectrodes Based on Os-Complex Modified Electrodeposition Polymers and Carbon Nanotubes. J. Electrochem. Soc. 2014, 161, H3058-H3063.

(62) Pinyou, P.; Poller, S.; Chen, X. X.; Schuhmann, W. Optimization of Os-Complex Modified Redox Polymers for Improving Biocatalysis of Pqq-Sgdh Based Electrodes. Electroanalysis 2015, 27, 200-208.

(63) Plamper, F. A. Changing Polymer Solvation by Electrochemical Means: Basics and Applications. In Porous Carbons - Hyperbranched Polymers - Polymer Solvation, Long, T. E.; Voit, B.; Okay, O., Eds.; Springer International Publishing: Cham, 2015, pp 125-212.

(64) Ackermann, Y.; Guschin, D. A.; Eckhard, K.; Shleev, S.; Schuhmann, W. Design of a Bioelectrocatalytic Electrode Interface for Oxygen Reduction in Biofuel Cells Based on a Specifically Adapted Os-Complex Containing Redox Polymer with Entrapped Trametes Hirsuta Laccase. Electrochem. Commun. 2010, 12, 640-643. 
(65) Karnicka, K.; Eckhard, K.; Guschin, D. A.; Stoica, L.; Kulesza, P. J.; Schuhmann, W. Visualisation of the Local Bio-Electrocatalytic Activity in Biofuel Cell Cathodes by Means of Redox Competition Scanning Electrochemical Microscopy (Rc-Secm). Electrochem. Commun. 2007, 9, 1998-2002.

(66) Stoica, L.; Dimcheva, N.; Ackermann, Y.; Karnicka, K.; Guschin, D. A.; Kulesza, P. J.; Rogalski, J.; Haltrich, D.; Ludwig, R.; Gorton, L.; Schuhmann, W. Membrane-Less Biofuel Cell Based on Cellobiose Dehydrogenase (Anode)/Laccase (Cathode) Wired Via Specific Os-Redox Polymers. Fuel Cells 2009, 9, 53-62.

(67) Suginta, W.; Khunkaewla, P.; Schulte, A. Electrochemical Biosensor Applications of Polysaccharides Chitin and Chitosan. Chem. Rev. 2013, 113, 5458-5479.

(68) Luo, X. L.; Xu, J. J.; Du, Y.; Chen, H. Y. A Glucose Biosensor Based on Chitosan-Glucose Oxidase-Gold Nanoparticles Biocomposite Formed by One-Step Electrodeposition. Anal. Biochem. 2004, 334, 284-289.

(69) Du, Y.; Luo, X. L.; Xu, J. J.; Chen, H. Y. A Simple Method to Fabricate a Chitosan-Gold Nanoparticles Film and Its Application in Glucose Biosensor. Bioelectrochemistry 2007, 70, 342-347.

(70) Zhou, Q. M.; Xie, Q. J.; Fu, Y. C.; Su, Z. H.; Jia, X.; Yao, S. Z. Electrodeposition of Carbon Nanotubes-Chitosan-Glucose Oxidase Biosensing Composite Films Triggered by Reduction of P-Benzoquinone or H2o2. J. Phys. Chem. B 2007, 111, 11276-11284.

(71) Li, J. J.; Yuan, R.; Chai, Y. Q. Simple Construction of an Enzymatic Glucose Biosensor Based on a Nanocomposite Film Prepared in One Step from Iron Oxide, Gold Nanoparticles, and Chitosan. Microchim. Acta 2011, 173, 369-374.

(72) Song, Y. H.; Liu, H. Y.; Wang, Y.; Wang, L. A Glucose Biosensor Based on Cytochrome C and Glucose Oxidase Co-Entrapped in Chitosan- Gold Nanoparticles Modified Electrode. Anal. Methods 2013, 5, 4165-4171.

(73) Tangkuaram, T.; Ponchio, C.; Kangkasomboon, T.; Katikawong, P.; Veerasai, W. Design and Development of a Highly Stable Hydrogen Peroxide Biosensor on Screen Printed Carbon Electrode Based on Horseradish Peroxidase Bound with Gold Nanoparticles in the Matrix of Chitosan. Biosens. Bioelectron. 2007, 22, 2071-2078.

(74) Luo, X. L.; Xu, J. J.; Wang, J. L.; Chen, H. Y. Electrochemically Deposited Nanocomposite of Chitosan and Carbon Nanotubes for Biosensor Application. Chem. Commun. 2005, 0, 21692171.

(75) Liang, R. P.; Fan, L. X.; Wang, R.; Qiu, J. D. One-Step Electrochemically Deposited Nanocomposite Film of Cs-Fc/Mwnts/God for Glucose Biosensor Application. Electroanalysis 2009, 21, 1685-1691.

(76) Che, X.; Yuan, R.; Chai, Y. Q.; Li, J. J.; Song, Z. J.; Li, W. J.; Zhong, X. A Glucose Biosensor Based on Chitosan-Prussian Blue-Multiwall Carbon Nanotubes-Hollow Ptco Nanochains Formed by One-Step Electrodeposition. Colloids Surf., B 2011, 84, 454-461. (77) Xu, J. J.; Luo, X. L.; Du, Y.; Chen, H. Y. Application of Mno2 Nanoparticles as an Eliminator of Ascorbate Interference to Amperometric Glucose Biosensors. Electrochem. Commun. 2004, 6, 1169-1173.

(78) Bai, Y. H.; Zhang, H.; Xu, J. J.; Chen, H. Y. Relationship between Nanostructure and Electrochemical/Biosensing Properties of Mno2 Nanomaterials for H2o2/Choline. J. Phys. Chem. C 2008, 112, 18984-18990. 
(79) Yang, J.; Yu, J. H.; Strickler, J. R.; Chang, W. J.; Gunasekaran, S. Nickel NanoparticleChitosan-Reduced Graphene Oxide-Modified Screen-Printed Electrodes for Enzyme-Free Glucose Sensing in Portable Microfluidic Devices. Biosens. Bioelectron. 2013, 47, 530-538. (80) Yang, S. L.; Lu, Z. Z.; Luo, S. L.; Liu, C. B.; Tang, Y. H. Direct Electrodeposition of a Biocomposite Consisting of Reduced Graphene Oxide, Chitosan and Glucose Oxidase on a Glassy Carbon Electrode for Direct Sensing of Glucose. Microchim. Acta 2013, 180, 127-135. (81) Lu, Z. Z.; Yang, S. L.; Yang, Q.; Luo, S. L.; Liu, C. B.; Tang, Y. H. A Glassy Carbon Electrode Modified with Graphene, Gold Nanoparticles and Chitosan for Ultrasensitive Determination of Lead(Ii). Microchim. Acta 2013, 180, 555-562.

(82) Xi, F. N.; Liu, L. J.; Wu, Q.; Lin, X. F. One-Step Construction of Biosensor Based on Chitosan-Ionic Liquid-Horseradish Peroxidase Biocomposite Formed by Electrodeposition. Biosens. Bioelectron. 2008, 24, 29-34.

(83) Zeng, X. D.; Li, X. F.; Xing, L.; Liu, X. Y.; Luo, S. L.; Wei, W. Z.; Kong, B.; Li, Y. H. Electrodeposition of Chitosan-Ionic Liquid-Glucose Oxidase Biocomposite onto Nano-Gold Electrode for Amperometric Glucose Sensing. Biosens. Bioelectron. 2009, 24, 2898-2903. (84) Xue, M. H.; Xu, Q.; Zhou, M.; Zhu, J. J. In Situ Immobilization of Glucose Oxidase in Chitosan-Gold Nanoparticle Hybrid Film on Prussian Blue Modified Electrode for HighSensitivity Glucose Detection. Electrochem. Commun. 2006, 8, 1468-1474.

(85) Wang, X. Y.; Gu, H. F.; Yin, F.; Tu, Y. F. A Glucose Biosensor Based on Prussian Blue/Chitosan Hybrid Film. Biosens. Bioelectron. 2009, 24, 1527-1530.

(86) Du, D.; Ding, J. W.; Cai, J.; Zhang, A. D. One-Step Electrochemically Deposited Interface of Chitosan-Gold Nanoparticles for Acetylcholinesterase Biosensor Design. J. Electroanal. Chem. 2007, 605, 53-60.

(87) Song, Y. H.; Zhang, M.; Wang, L.; Wan, L. L.; Xiao, X. P.; Ye, S. H.; Wang, J. R. A Novel Biosensor Based on Acetylecholinesterase/Prussian Blue-Chitosan Modified Electrode for Detection of Carbaryl Pesticides. Electrochim. Acta 2011, 56, 7267-7271.

(88) Zhai, C.; Sun, X.; Zhao, W. P.; Gong, Z. L.; Wang, X. Y. Acetylcholinesterase Biosensor Based on Chitosan/Prussian Blue/Multiwall Carbon Nanotubes/Hollow Gold Nanospheres Nanocomposite Film by One-Step Electrodeposition. Biosens. Bioelectron. 2013, 42, 124-130. (89) Du, D.; Ding, J. W.; Cai, J.; Zhang, A. D. Electrochemical Thiocholine Inhibition Sensor Based on Biocatalytic Growth of Au Nanoparticles Using Chitosan as Template. Sens. Actuators, B 2007, 127, 317-322.

(90) Du, D.; Ding, J. W.; Cai, J.; Zhang, A. D. Determination of Carbaryl Pesticide Using Amperometric Acetylcholinesterase Sensor Formed by Electrochemically Deposited Chitosan. Colloids Surf., B 2007, 58, 145-150.

(91) Gong, J. M.; Liu, T.; Song, D. D.; Zhang, X. B.; Zhang, L. Z. One-Step Fabrication of Three-Dimensional Porous Calcium Carbonate-Chitosan Composite Film as the Immobilization Matrix of Acetylcholinesterase and Its Biosensing on Pesticide. Electrochem. Commun. 2009, $11,1873-1876$.

(92) Bai, Y. H.; Du, Y.; Xu, J. J.; Chen, H. Y. Choline Biosensors Based on a Bi-Electrocatalytic Property of Mno2 Nanoparticles Modified Electrodes to H2o2. Electrochem. Commun. 2007, 9 , 2611-2616.

(93) Diaconu, M.; Litescu, S. C.; Radu, G. L. Laccase-Mwcnt-Chitosan Biosensor-a New Tool for Total Polyphenolic Content Evaluation from in Vitro Cultivated Plants. Sens. Actuators, B 2010, 145, 800-806. 
(94) Wang, L.; Wen, W.; Xiong, H. Y.; Zhang, X. H.; Gu, H. S.; Wang, S. F. A Novel Amperometric Biosensor for Superoxide Anion Based on Superoxide Dismutase Immobilized on Gold Nanoparticle-Chitosan-Ionic Liquid Biocomposite Film. Anal. Chim. Acta 2013, 758, 6671.

(95) Ye, H. Z.; Xu, H. F.; Xu, X. Q.; Zheng, C. S.; Li, X. H.; Wang, L. L.; Liu, X. X.; Chen, G. N. An Electrochemiluminescence Sensor for Adrenaline Assay Based on the Tyrosinase/Sic/Chitosan Modified Electrode. Chem. Commun. 2013, 49, 7070-7072.

(96) Chen, P. C.; Chen, R. L. C.; Cheng, T. J.; Wittstock, G. Localized Deposition of Chitosan as Matrix for Enzyme Immobilization. Electroanalysis 2009, 21, 804-810.

(97) Wang, B. B.; Ji, X. P.; Zhao, H. Y.; Wang, N.; Li, X. R.; Ni, R. X.; Liu, Y. H. An Amperometric Beta-Glucan Biosensor Based on the Immobilization of Bi-Enzyme on Prussian Blue-Chitosan and Gold Nanoparticles-Chitosan Nanocomposite Films. Biosens. Bioelectron. 2014, 55, 113-119.

(98) Li, F.; Wang, Z.; Chen, W.; Zhang, S. S. A Simple Strategy for One-Step Construction of Bienzyme Biosensor by in-Situ Formation of Biocomposite Film through Electrodeposition. Biosens. Bioelectron. 2009, 24, 3030-3035.

(99) Luo, X. L.; Xu, J. J.; Zhang, Q.; Yang, G. J.; Chen, H. Y. Electrochemically Deposited Chitosan Hydrogel for Horseradish Peroxidase Immobilization through Gold Nanoparticles SelfAssembly. Biosens. Bioelectron. 2005, 21, 190-196.

(100) Meyer, W. L.; Liu, Y.; Shi, X. W.; Yang, X. H.; Bentley, W. E.; Payne, G. F. ChitosanCoated Wires: Conferring Electrical Properties to Chitosan Fibers. Biomacromolecules 2009, 10, 858-864.

(101) Liu, C. H.; Guo, X. L.; Cui, H. T.; Yuan, R. An Amperometric Biosensor Fabricated from Electro-Co-Deposition of Sodium Alginate and Horseradish Peroxidase. J. Mol. Catal. B: Enzym. 2009, 60, 151-156.

(102) Poller, S.; Schuhmann, W. A Miniaturized Voltammetric Ph Sensor Based on Optimized Redox Polymers. Electrochim. Acta 2014, 140, 101-107.

(103) Loget, G.; Roche, J.; Gianessi, E.; Bouffier, L.; Kuhn, A. Indirect Bipolar

Electrodeposition. J. Am. Chem. Soc. 2012, 134, 20033-20036.

(104) Yu, Z. Y.; Wang, C. F.; Ling, L. T.; Chen, L.; Chen, S. Triphase Microfluidic-Directed Self-Assembly: Anisotropic Colloidal Photonic Crystal Supraparticles and Multicolor Patterns Made Easy. Angew. Chem., Int. Ed. Engl. 2012, 51, 2375-2378.

(105) MansouriMajd, S.; Teymourian, H.; Salimi, A.; Hallaj, R. Fabrication of Electrochemical Theophylline Sensor Based on Manganese Oxide Nanoparticles/Ionic Liquid/Chitosan Nanocomposite Modified Glassy Carbon Electrode. Electrochim. Acta 2013, 108, 707-716. (106) Bai, Y. H.; Xu, J. J.; Chen, H. Y. Selective Sensing of Cysteine on Manganese Dioxide Nanowires and Chitosan Modified Glassy Carbon Electrodes. Biosens. Bioelectron. 2009, 24, 2985-2990.

(107) Liu, B. Z.; Deng, Y. H.; Hu, X. B.; Gao, Z. Q.; Sun, C. Electrochemical Sensing of Trichloroacetic Acid Based on Silver Nanoparticles Doped Chitosan Hydrogel Film Prepared with Controllable Electrodeposition. Electrochim. Acta 2012, 76, 410-415.

(108) Santos, R. M.; Rodrigues, M. S.; Laranjinha, J.; Barbosa, R. M. Biomimetic Sensor Based on Hemin/Carbon Nanotubes/Chitosan Modified Microelectrode for Nitric Oxide Measurement in the Brain. Biosens. Bioelectron. 2013, 44, 152-159. 
(109) Hao, C.; Ding, L.; Zhang, X. J.; Ju, H. X. Biocompatible Conductive Architecture of Carbon Nanofiber-Doped Chitosan Prepared with Controllable Electrodeposition for Cytosensing. Anal. Chem. 2007, 79, 4442-4447.

(110) Li, S. S.; Du, D.; Huang, J.; Tu, H. Y.; Yang, Y. Q.; Zhang, A. D. One-Step Electrodeposition of a Molecularly Imprinting Chitosan/Phenyltrimethoxysilane/Aunps Hybrid Film and Its Application in the Selective Determination of P-Nitrophenol. Analyst 2013, 138, 2761-2768.

(111) Liang, R. P.; Peng, H. Z.; Qiu, J. D. Fabrication, Characterization, and Application of Potentiometric Immunosensor Based on Biocompatible and Controllable Three-Dimensional Porous Chitosan Membranes. J. Colloid Interface Sci. 2008, 320, 125-131.

(112) Qiu, J. D.; Liang, R. P.; Wang, R.; Fan, L. X.; Chen, Y. W.; Xia, X. H. A Label-Free Amperometric Immunosensor Based on Biocompatible Conductive Redox ChitosanFerrocene/Gold Nanoparticles Matrix. Biosens. Bioelectron. 2009, 25, 852-857.

(113) Yi, H. M.; Wu, L. Q.; Sumner, J. J.; Gillespie, J. B.; Payne, G. F.; Bentley, W. E. Chitosan Scaffolds for Biomolecular Assembly: Coupling Nucleic Acid Probes for Detecting Hybridization. Biotechnol. Bioeng. 2003, 83, 646-652.

(114) Yi, H. M.; Wu, L. Q.; Ghodssi, R.; Rubloff, G. W.; Payne, G. F.; Bentley, W. E. A Robust Technique for Assembly of Nucleic Acid Hybridization Chips Based on Electrochemically Templated Chitosan. Anal. Chem. 2004, 76, 365-372.

(115) Yi, H. M.; Wu, L. Q.; Ghodssi, R.; Rubloff, G. W.; Payne, G. F.; Bentley, W. E. SignalDirected Sequential Assembly of Biomolecules on Patterned Surfaces. Langmuir 2005, 21, 21042107.

(116) Koev, S. T.; Powers, M. A.; Yi, H.; Wu, L. Q.; Bentley, W. E.; Rubloff, G. W.; Payne, G. F.; Ghodssi, R. Mechano-Transduction of DNA Hybridization and Dopamine Oxidation through Electrodeposited Chitosan Network. Lab on a Chip 2007, 7, 103-111.

(117) Yi, H. M.; Nisar, S.; Lee, S. Y.; Powers, M. A.; Bentley, W. E.; Payne, G. F.; Ghodssi, R.; Rubloff, G. W.; Harris, M. T.; Culver, J. N. Patterned Assembly of Genetically Modified Viral Nanotemplates Via Nucleic Acid Hybridization. Nano Lett. 2005, 5, 1931-1936.

(118) Shi, X. W.; Liu, Y.; Lewandowski, A. T.; Wu, L. Q.; Wu, H. C.; Ghodssi, R.; Rubloff, G. W.; Bentley, W. E.; Payne, G. F. Chitosan Biotinylation and Electrodeposition for Selective Protein Assembly. Macromol. Biosci. 2008, 8, 451-457.

(119) Shi, X. W.; Yang, X. H.; Gaskell, K. J.; Liu, Y.; Kobatake, E.; Bentley, W. E.; Payne, G. F. Reagentless Protein Assembly Triggered by Localized Electrical Signals. Adv. Mater. 2009, 21, 984-988.

(120) Shi, X. W.; Qiu, L.; Nie, Z.; Xiao, L.; Payne, G. F.; Du, Y. M. Protein Addressing on Patterned Microchip by Coupling Chitosan Electrodeposition and 'Electro-Click' Chemistry. Biofabrication 2013, 5, 041001.

(121) Kim, E.; Liu, Y.; Shi, X. W.; Yang, X. H.; Bentley, W. E.; Payne, G. F. Biomimetic Approach to Confer Redox Activity to Thin Chitosan Films. Adv. Funct. Mater. 2010, 20, 26832694.

(122) Kim, E.; Gordonov, T.; Liu, Y.; Bentley, W. E.; Payne, G. F. Reverse Engineering to Suggest Biologically Relevant Redox Activities of Phenolic Materials. ACS Chem. Biol. 2013, 8, 716-724.

(123) Kim, E.; Liu, Y.; Bentley, W. E.; Payne, G. F. Redox Capacitor to Establish Bio-Device Redox-Connectivity. Adv. Funct. Mater. 2012, 22, 1409-1416. 
(124) Liu, Y.; Zhang, B. C.; Javvaji, V.; Kim, E.; Lee, M. E.; Raghavan, S. R.; Wang, Q.; Payne, G. F. Tyrosinase-Mediated Grafting and Crosslinking of Natural Phenols Confers Functional Properties to Chitosan. Biochem. Eng. J. 2014, 89, 21-27.

(125) Liu, Y.; Kim, E.; White, I. M.; Bentley, W. E.; Payne, G. F. Information Processing through a Bio-Based Redox Capacitor: Signatures for Redox-Cycling. Bioelectrochemistry 2014, 98, 94-102.

(126) Kim, E.; Gordonov, T.; Bentley, W. E.; Payne, G. F. Amplified and in Situ Detection of Redox-Active Metabolite Using a Biobased Redox Capacitor. Anal. Chem. 2013, 85, 2102-2108. (127) Ben-Yoav, H.; Winkler, T. E.; Kim, E.; Chocron, S. E.; Kelly, D. L.; Payne, G. F.; Ghodssi, R. Redox Cycling-Based Amplifying Electrochemical Sensor for in Situ Clozapine Antipsychotic Treatment Monitoring. Electrochim. Acta 2014, 130, 497-503.

(128) Ben-Yoav, H.; Chocron, S. E.; Winkler, T. E.; Kim, E.; Kelly, D. L.; Payne, G. F.; Ghodssi, R. An Electrochemical Micro-System for Clozapine Antipsychotic Treatment Monitoring. Electrochim. Acta 2015, 163, 260-270.

(129) Winkler, T. E.; Ben-Yoav, H.; Chocron, S. E.; Kim, E.; Kelly, D. L.; Payne, G. F.; Ghodssi, R. Electrochemical Study of the Catechol-Modified Chitosan System for Clozapine Treatment Monitoring. Langmuir 2014, 30, 14686-14693.

(130) Kim, E.; Chocron, S. E.; Ben-Yoav, H.; Winkler, T. E.; Liu, Y.; Glassman, M.; Wolfram, C.; Kelly, D. L.; Ghodssi, R.; Payne, G. F. Programmable "Semismart" Sensor: Relevance to Monitoring Antipsychotics. Adv. Funct. Mater. 2015, 25, 2156-2165.

(131) Gordonov, T.; Kim, E.; Cheng, Y.; Ben-Yoav, H.; Ghodssi, R.; Rubloff, G.; Yin, J. J.; Payne, G. F.; Bentley, W. E. Electronic Modulation of Biochemical Signal Generation. Nat. Nanotechnol. 2014, 9, 605-610.

(132) Yang, X. H.; Shi, X. W.; Liu, Y.; Bentley, W. E.; Payne, G. F. Orthogonal Enzymatic Reactions for the Assembly of Proteins at Electrode Addresses. Langmuir 2009, 25, 338-344. (133) Li, Y.; Liu, Y.; Gao, T. R.; Zhang, B.; Song, Y. Y.; Terrell, J. L.; Barber, N.; Bentley, W. E.; Takeuchi, I.; Payne, G. F.; Wang, Q. Self-Assembly with Orthogonal-Imposed Stimuli to Impart Structure and Confer Magnetic Function to Electrodeposited Hydrogels. ACS Appl. Mater. Interfaces 2015, 7, 10587-10598.

(134) Krishnaraj, R. N.; Karthikeyan, R.; Berchmans, S.; Chandran, S.; Pal, P. Functionalization of Electrochemically Deposited Chitosan Films with Alginate and Prussian Blue for Enhanced Performance of Microbial Fuel Cells. Electrochim. Acta 2013, 112, 465-472.

(135) Wu, L. Q.; Lee, K.; Wang, X.; English, D. S.; Losert, W.; Payne, G. F. Chitosan-Mediated and Spatially Selective Electrodeposition of Nanoscale Particles. Langmuir 2005, 21, 3641-3646. (136) Li, Y.; Wu, K.; Zhitomirsky, I. Electrodeposition of Composite Zinc Oxide-Chitosan Films. Colloids Surf., A 2010, 356, 63-70.

(137) Wang, Y. F.; Geng, Z. H.; Guo, M. M.; Chen, Y. J.; Guo, X. C.; Wang, X.

Electroaddressing of Zns Quantum Dots by Codeposition with Chitosan to Construct Fluorescent and Patterned Device Surface. ACS Appl. Mater. Interfaces 2014, 6, 15510-15515.

(138) Wang, Y. F.; Wang, X.; Geng, Z. H.; Xiong, Y. F.; Wu, W. C.; Chen, Y. J.

Electrodeposition of a Carbon Dots/Chitosan Composite Produced by a Simple in Situ Method and Electrically Controlled Release of Carbon Dots. J. Mater. Chem. B 2015, 3, 7511-7517. (139) Yoshioka, T.; Chavez-Valdez, A.; Roether, J. A.; Schubert, D. W.; Boccaccini, A. R. Ac Electrophoretic Deposition of Organic-Inorganic Composite Coatings. J. Colloid Interface Sci. 2013, 392, 167-171. 
(140) Wang, Z. L.; Zhang, X. Q.; Gu, J. M.; Yang, H. T.; Nie, J.; Ma, G. P. Electrodeposition of Alginate/Chitosan Layer-by-Layer Composite Coatings on Titanium Substrates. Carbohydr.

Polym. 2014, 103, 38-45.

(141) Cassani, D. A. D.; Altomare, L.; De Nardo, L.; Variola, F. Physicochemical and Nanomechanical Investigation of Electrodeposited Chitosan:Peo Blends. J. Mater. Chem. B 2015, 3, 2641-2650.

(142) Jiang, T.; Zhang, Z.; Zhou, Y.; Liu, Y.; Wang, Z. W.; Tong, H.; Shen, X. Y.; Wang, Y. N. Surface Functionalization of Titanium with Chitosan/Gelatin Via Electrophoretic Deposition: Characterization and Cell Behavior. Biomacromolecules 2010, 11, 1254-1260.

(143) Patel, K. D.; Kim, T. H.; Lee, E. J.; Han, C. M.; Lee, J. Y.; Singh, R. K.; Kim, H. W.

Nanostructured Biointerfacing of Metals with Carbon Nanotube/Chitosan Hybrids by Electrodeposition for Cell Stimulation and Therapeutics Delivery. ACS Appl. Mater. Interfaces 2014, 6, 20214-20224.

(144) Redepenning, J.; Venkataraman, G.; Chen, J.; Stafford, N. Electrochemical Preparation of Chitosan/Hydroxyapatite Composite Coatings on Titanium Substrates. J. Biomed. Mater. Res. A 2003, 66A, 411-416.

(145) Zhitomirsky, I. Electrophoretic Deposition of Organic-Inorganic Nanocomposites. J. Mater. Sci. 2006, 41, 8186-8195.

(146) Boccaccini, A. R.; Keim, S.; Ma, R.; Li, Y.; Zhitomirsky, I. Electrophoretic Deposition of Biomaterials. J. R. Soc., Interface 2010, 7, S581-S613.

(147) Zhitomirsky, D.; Roether, J. A.; Boccaccini, A. R.; Zhitomirsky, I. Electrophoretic Deposition of Bioactive Glass/Polymer Composite Coatings with and without Ha Nanoparticle Inclusions for Biomedical Applications. J. Mater. Process. Technol. 2009, 209, 1853-1860. (148) Pishbin, F.; Simchi, A.; Ryan, M. P.; Boccaccini, A. R. Electrophoretic Deposition of Chitosan/45s5 Bioglass (R) Composite Coatings for Orthopaedic Applications. Surf. Coat.

Technol. 2011, 205, 5260-5268.

(149) Seuss, S.; Lehmann, M.; Boccaccini, A. R. Alternating Current Electrophoretic Deposition of Antibacterial Bioactive Glass-Chitosan Composite Coatings. Int. J. Mol. Sci. 2014, 15, 12231 12242.

(150) Patel, K. D.; El-Fiqi, A.; Lee, H. Y.; Singh, R. K.; Kim, D. A.; Lee, H. H.; Kim, H. W. Chitosan-Nanobioactive Glass Electrophoretic Coatings with Bone Regenerative and Drug Delivering Potential. J. Mater. Chem. 2012, 22, 24945-24956.

(151) Pang, X.; Zhitomirsky, I. Electrodeposition of Composite Hydroxyapatite-Chitosan Films. Mater. Chem. Phys. 2005, 94, 245-251.

(152) Pang, X.; Zhitomirsky, I. Electrophoretic Deposition of Composite HydroxyapatiteChitosan Coatings. Mater. Charact. 2007, 58, 339-348.

(153) Pang, X.; Casagrande, T.; Zhitomirsky, I. Electrophoretic Deposition of HydroxyapatiteCasio3-Chitosan Composite Coatings. J. Colloid Interface Sci. 2009, 330, 323-329.

(154) Grandfield, K.; Sun, F.; FitzPatrick, M.; Cheong, M.; Zhitomirsky, I. Electrophoretic Deposition of Polymer-Carbon Nanotube-Hydroxyapatite Composites. Surf. Coat. Technol. 2009, 203, 1481-1487.

(155) Batmanghelich, F.; Ghorbani, M. Effect of Ph and Carbon Nanotube Content on the Corrosion Behavior of Electrophoretically Deposited Chitosan-Hydroxyapatite-Carbon Nanotube Composite Coatings. Ceram. Int. 2013, 39, 5393-5402. 
(156) Raddaha, N. S.; Cordero-Arias, L.; Cabanas-Polo, S.; Virtanen, S.; Roether, J. A.;

Boccaccini, A. R. Electrophoretic Deposition of Chitosan/H-Bn and Chitosan/H-Bn/Tio2 Composite Coatings on Stainless Steel (3161) Substrates. Materials 2014, 7, 1814-1829.

(157) Deen, I.; Pang, X.; Zhitomirsky, I. Electrophoretic Deposition of Composite ChitosanHalloysite Nanotube-Hydroxyapatite Films. Colloids Surf., A 2012, 410, 38-44.

(158) Deen, I.; Zhitomirsky, I. Electrophoretic Deposition of Composite Halloysite NanotubeHydroxyapatite-Hyaluronic Acid Films. J. Alloys Compd. 2014, 586, S531-S534.

(159) Cordero-Arias, L.; Cabanas-Polo, S.; Gilabert, J.; Goudouri, O. M.; Sanchez, E.; Virtanen, S.; Boccaccini, A. R. Electrophoretic Deposition of Nanostructured Tio2/Alginate and Tio2Bioactive Glass/Alginate Composite Coatings on Stainless Steel. Adv. Appl. Ceram. 2014, 113, 42-49.

(160) Chen, Q.; de Larraya, U. P.; Garmendia, N.; Lasheras-Zubiate, M.; Cordero-Arias, L.; Virtanen, S.; Soccaccini, A. R. Electrophoretic Deposition of Cellulose Nanocrystals (Cns) and Cns/Alginate Nanocomposite Coatings and Free Standing Membranes. Colloids Surf., B 2014, $118,41-48$.

(161) Pang, X.; Zhitomirsky, I. Electrodeposition of Hydroxyapatite-Silver-Chitosan Nanocomposite Coatings. Surf. Coat. Technol. 2008, 202, 3815-3821.

(162) Pishbin, F.; Mourino, V.; Gilchrist, J. B.; McComb, D. W.; Kreppel, S.; Salih, V.; Ryan, M. P.; Boccaccini, A. R. Single-Step Electrochemical Deposition of Antimicrobial Orthopaedic Coatings Based on a Bioactive Glass/Chitosan/Nano-Silver Composite System. Acta Biomater. 2013, 9, 7469-7479.

(163) Li, P. H.; Zhang, X. M.; Xu, R. Z.; Wang, W. H.; Liu, X. M.; Yeung, K. W. K.; Chu, P. K. Electrochemically Deposited Chitosan/Ag Complex Coatings on Biomedical Niti Alloy for Antibacterial Application. Surf. Coat. Technol. 2013, 232, 370-375.

(164) Wang, Y. F.; Guo, X. C.; Pan, R. H.; Han, D.; Chen, T.; Geng, Z. H.; Xiong, Y. F.; Chen, Y. J. Electrodeposition of Chitosan/Gelatin/Nanosilver: A New Method for Constructing Biopolymer/Nanoparticle Composite Films with Conductivity and Antibacterial Activity. Mater. Sci. Eng., C 2015, 53, 222-228.

(165) Ordikhani, F.; Tamjid, E.; Simchi, A. Characterization and Antibacterial Performance of Electrodeposited Chitosan-Vancomycin Composite Coatings for Prevention of ImplantAssociated Infections. Mater. Sci. Eng., C 2014, 41, 240-248.

(166) Ordikhani, F.; Simchi, A. Long-Term Antibiotic Delivery by Chitosan-Based Composite Coatings with Bone Regenerative Potential. Appl. Surf. Sci. 2014, 317, 56-66.

(167) Pishbin, F.; Mourino, V.; Flor, S.; Kreppel, S.; Salih, V.; Ryan, M. P.; Boccaccini, A. R. Electrophoretic Deposition of Gentamicin-Loaded Bioactive Glass/Chitosan Composite Coatings for Orthopaedic Implants. ACS Appl. Mater. Interfaces 2014, 6, 8796-8806.

(168) Zhao, P. K.; Liu, Y. Y.; Xiao, L.; Deng, H. B.; Du, Y. M.; Shi, X. W. Electrochemical Deposition to Construct a Nature Inspired Multilayer Chitosan/Layered Double Hydroxides Hybrid Gel for Stimuli Responsive Release of Protein. J. Mater. Chem. B 2015, 3, 7577-7584. (169) Liu, Y. Y.; Yan, K.; Jiang, G. X.; Xiong, Y.; Du, Y. M.; Shi, X. W. Electrical Signal Guided Ibuprofen Release from Electrodeposited Chitosan Hydrogel. Int. J. Polym. Sci. 2014, ID 736898.

(170) Zhao, P. K.; Liu, H. Y.; Deng, H. B.; Xiao, L.; Qin, C. Q.; Du, Y. M.; Shi, X. W. A Study of Chitosan Hydrogel with Embedded Mesoporous Silica Nanoparticles Loaded by Ibuprofen as a Dual Stimuli-Responsive Drug Release System for Surface Coating of Titanium Implants. Colloids Surf., B 2014, 123, 657-663. 
(171) Patel, K. D.; Singh, R. K.; Lee, E. J.; Han, C. M.; Won, J. E.; Knowles, J. C.; Kim, H. W. Tailoring Solubility and Drug Release from Electrophoretic Deposited Chitosan-Gelatin Films on Titanium. Surf. Coat. Technol. 2014, 242, 232-236.

(172) Fusco, S.; Chatzipirpiridis, G.; Sivaraman, K. M.; Ergeneman, O.; Nelson, B. J.; Pane, S. Chitosan Electrodeposition for Microrobotic Drug Delivery. Adv. Healthc. Mater. 2013, 2, 1037 1044.

(173) Chen, Q.; Li, W.; Goudouria, O. M.; Ding, Y. P.; Cabanas-Polo, S.; Boccaccini, A. R. Electrophoretic Deposition of Antibiotic Loaded Phbv Microsphere-Alginate Composite Coating with Controlled Delivery Potential. Colloids Surf., B 2015, 130, 199-206.

(174) Cordero-Arias, L.; Cabanas-Polo, S.; Goudouri, O. M.; Misra, S. K.; Gilabert, J.; ValsamiJones, E.; Sanchez, E.; Virtanen, S.; Boccaccini, A. R. Electrophoretic Deposition of Zno/Alginate and Zno-Bioactive Glass/Alginate Composite Coatings for Antimicrobial Applications. Mater. Sci. Eng., C 2015, 55, 137-144.

(175) Leisk, G. G.; Lo, T. J.; Yucel, T.; Lu, Q.; Kaplan, D. L. Electrogelation for Protein Adhesives. Adv. Mater. 2010, 22, 711-715.

(176) Maniglio, D.; Bonani, W.; Bortoluzzi, G.; Servoli, E.; Motta, A.; Migliaresi, C. Electrodeposition of Silk Fibroin on Metal Substrates. J. Bioact. Compat. Polym. 2010, 25, 441454.

(177) Inoue, S.; Tanaka, K.; Arisaka, F.; Kimura, S.; Ohtomo, K.; Mizuno, S. Silk Fibroin of Bombyx Mori Is Secreted, Assembling a High Molecular Mass Elementary Unit Consisting of H-Chain, L-Chain, and P25, with a $6: 6: 1$ Molar Ratio. J. Biol. Chem. 2000, 275, 40517-40528. (178) Zhou, C. Z.; Confalonieri, F.; Medina, N.; Zivanovic, Y.; Esnault, C.; Yang, T.; Jacquet, M.; Janin, J.; Duguet, M.; Perasso, R.; Li, Z. G. Fine Organization of Bombyx Mori Fibroin Heavy Chain Gene. Nucleic Acids Res. 2000, 28, 2413-2419.

(179) Yucel, T.; Kojic, N.; Leisk, G. G.; Lo, T. J.; Kaplan, D. L. Non-Equilibrium Silk Fibroin Adhesives. J. Struct. Biol. 2010, 170, 406-412.

(180) Lu, Q.; Huang, Y. L.; Li, M. Z.; Zuo, B. Q.; Lu, S. Z.; Wang, J. N.; Zhu, H. S.; Kaplan, D. L. Silk Fibroin Electrogelation Mechanisms. Acta Biomater. 2011, 7, 2394-2400.

(181) Kojic, N.; Panzer, M. J.; Leisk, G. G.; Raja, W. K.; Kojic, M.; Kaplan, D. L. Ion Electrodiffusion Governs Silk Electrogelation. Soft Matter 2012, 8, 6897-6905.

(182) Bressner, J. E.; Marelli, B.; Qin, G. K.; Klinker, L. E.; Zhang, Y. J.; Kaplan, D. L.; Omenetto, F. G. Rapid Fabrication of Silk Films with Controlled Architectures Via Electrogelation. J. Mater. Chem. B 2014, 2, 4983-4987.

(183) Tabatabai, A. P.; Kaplan, D. L.; Blair, D. L. Rheology of Reconstituted Silk Fibroin Protein Gels: The Epitome of Extreme Mechanics. Soft Matter 2015, 11, 756-761.

(184) Jose, R. R.; Elia, R.; Tien, L. W.; Kaplan, D. L. Electroresponsive Aqueous Silk Protein as "Smart" Mechanical Damping Fluid. ACS Appl. Mater. Interfaces 2014, 6, 6212-6216. (185) Lin, Y. N.; Xia, X. X.; Shang, K.; Elia, R.; Huang, W. E.; Cebe, P.; Leisk, G.; Omenetto, F.; Kaplan, D. L. Tuning Chemical and Physical Cross-Links in Silk Electrogels for Morphological Analysis and Mechanical Reinforcement. Biomacromolecules 2013, 14, 26292635.

(186) Elia, R.; Michelson, C. D.; Perera, A. L.; Brunner, T. F.; Harsono, M.; Leisk, G. G.; Kugel, G.; Kaplan, D. L. Electrodeposited Silk Coatings for Bone Implants. J. Biomed. Mater. Res. B 2015, 103, 1602-1609. 
(187) Zhang, Z.; Qu, Y. Y.; Li, X. S.; Zhang, S.; Wei, Q. S.; Shi, Y. S.; Chen, L. L. Electrophoretic Deposition of Tetracycline Modified Silk Fibroin Coatings for Functionlization of Titanium Surfaces. Appl. Surf. Sci. 2014, 303, 255-262.

(188) Ammam, M. Electrochemical and Electrophoretic Deposition of Enzymes: Principles, Differences and Application in Miniaturized Biosensor and Biofuel Cell Electrodes. Biosens.

Bioelectron. 2014, 58, 121-131.

(189) Ammam, M. Electrophoretic Deposition under Modulated Electric Fields: A Review. Rsc Advances 2012, 2, 7633-7646.

(190) Wang, S. S.; Vieth, W. R. Collagen-Enzyme Complex Membranes and Their Performance in Biocatalytic Modules. Biotechnol. Bioeng. 1973, 15, 93-115.

(191) Im, D. M.; Jang, D. H.; Oh, S. M.; Striebel, C.; Wiemhofer, H. D.; Gauglitz, G.; Gopel, W. Electrodeposited God/Bsa Electrodes - Ellipsometric Study and Glucose-Sensing Behavior. Sens. Actuators, B 1995, 24, 149-155.

(192) Strike, D. J.; Derooij, N. F.; Koudelkahep, M. Electrodeposition of Glucose-Oxidase for the Fabrication of Miniature Sensors. Sens. Actuators, B 1993, 13, 61-64.

(193) Matsumoto, N.; Chen, X. H.; Wilson, G. S. Fundamental Studies of Glucose Oxidase Deposition on a Pt Electrode. Anal. Chem. 2002, 74, 362-367.

(194) Chen, X. H.; Matsumoto, N.; Hu, Y. B.; Wilson, G. S. Electrochemically Mediated Electrodeposition/Electropolymerization to Yield a Glucose Microbiosensor with Improved Characteristics. Anal. Chem. 2002, 74, 368-372.

(195) Stonehuerner, J. G.; Zhao, J.; Odaly, J. P.; Crumbliss, A. L.; Henkens, R. W. Comparison of Colloidal Gold Electrode Fabrication Methods - the Preparation of a Horseradish-Peroxidase Enzyme Electrode. Biosens. Bioelectron. 1992, 7, 421-428.

(196) Palys, B.; Marzec, M.; Rogalski, J. Poly-O-Aminophenol as a Laccase Mediator and Influence of the Enzyme on the Polymer Electrodeposition. Bioelectrochemistry 2010, 80, 43-48. (197) Hoshi, T.; Anzai, J.; Osa, T. Electrochemical Deposition of Avidin on the Surface of a Platinum-Electrode for Enzyme Sensor Applications. Anal. Chim. Acta 1994, 289, 321-327. (198) Mignani, A.; Scavetta, E.; Tonelli, D. Electrodeposited Glucose Oxidase/Anionic Clay for Glucose Biosensors Design. Anal. Chim. Acta 2006, 577, 98-106.

(199) Chiu, J. Y.; Yu, C. M.; Yen, M. J.; Chen, L. C. Glucose Sensing Electrodes Based on a Poly(3,4-Ethylenedioxythiophene)/Prussian Blue Bilayer and Multi-Walled Carbon Nanotubes. Biosens. Bioelectron. 2009, 24, 2015-2020.

(200) Lim, S. H.; Wei, J.; Lin, J. Y.; Li, Q. T.; KuaYou, J. A Glucose Biosensor Based on Electrodeposition of Palladium Nanoparticles and Glucose Oxidase onto Nafion-Solubilized Carbon Nanotube Electrode. Biosens. Bioelectron. 2005, 20, 2341-2346.

(201) Ammam, M.; Fransaer, J. Micro-Biofuel Cell Powered by Glucose/O-2 Based on ElectroDeposition of Enzyme, Conducting Polymer and Redox Mediators: Preparation, Characterization and Performance in Human Serum. Biosens. Bioelectron. 2010, 25, 1474-1480.

(202) Gao, Z. Q.; Binyamin, G.; Kim, H. H.; Barton, S. C.; Zhang, Y. C.; Heller, A. Electrodeposition of Redox Polymers and Co-Electrodeposition of Enzymes by Coordinative Crosslinking. Angew. Chem., Int. Ed. Engl. 2002, 41, 810-813.

(203) Ammam, M.; Fransaer, J. Ac-Electrophoretic Deposition of Glucose Oxidase. Biosens. Bioelectron. 2009, 25, 191-197.

(204) Ammam, M.; Fransaer, J. Two-Enzyme Lactose Biosensor Based on Beta-Galactosidase and Glucose Oxidase Deposited by Ac-Electrophoresis: Characteristics and Performance for Lactose Determination in Milk. Sens. Actuators, B 2010, 148, 583-589. 
(205) Ammam, M.; Fransaer, J. Glucose/O2 Biofuel Cell Based on Enzymes, Redox Mediators, and Multiple-Walled Carbon Nanotubes Deposited by Ac-Electrophoresis Then Stabilized by Electropolymerized Polypyrrole. Biotechnol. Bioeng. 2012, 109, 1601-1609.

(206) Ammam, M.; Fransaer, J. Combination of Laccase and Catalase in Construction of H2o2O-2 Based Biocathode for Applications in Glucose Biofuel Cells. Biosens. Bioelectron. 2013, 39 , 274-281.

(207) Ammam, M.; Fransaer, J. Ac-Electrophoretic Deposition of Metalloenzymes: Catalase as a Case Study for the Sensitive and Selective Detection of H2o2. Sens. Actuators, B 2011, 160, 1063-1069.

(208) Ammam, M.; Fransaer, J. Highly Sensitive and Selective Glutamate Microbiosensor Based on Cast Polyurethane/Ac-Electrophoresis Deposited Multiwalled Carbon Nanotubes and Then Glutamate Oxidase/Electrosynthesized Polypyrrole/Pt Electrode. Biosens. Bioelectron. 2010, 25, 1597-1602.

(209) Fraaije, J.; Kleijn, J. M.; Vandergraaf, M.; Dijt, J. C. Orientation of Adsorbed Cytochrome$\mathrm{C}$ as a Function of the Electrical Potential of the Interface Studied by Total Internal-Reflection Fluorescence. Biophys. J. 1990, 57, 965-975.

(210) Brusatori, M. A.; Van Tassel, P. R. Biosensing under an Applied Voltage Using Optical Waveguide Lightmode Spectroscopy. Biosens. Bioelectron. 2003, 18, 1269-1277.

(211) Khan, G. F.; Shinohara, H.; Ikariyama, Y.; Aizawa, M. Electrochemical-Behavior of Monolayer Quinoprotein Adsorbed on the Electrode Surface. J. Electroanal. Chem. 1991, 315, 263-273.

(212) Morrissey, B. W.; Smith, L. E.; Stromberg, R. R.; Fenstermaker, C. A. Ellipsometric Investigation of Effect of Potential on Blood Protein Conformation and Adsorbance. J. Colloid Interface Sci. 1976, 56, 557-563.

(213) Mattson, J. S.; Smith, C. A. Enhanced Protein Adsorption at the Solid-Solution Interface: Dependence on Surface Charge. Science 1973, 181, 1055-1057.

(214) Kleijn, J. M. Influence of the Electric Potential of the Interface on the Adsorption of Proteins. Colloids Surf., B 1994, 3, 91-100.

(215) Barten, D.; Kleijn, J. M.; Stuart, M. A. C. Adsorption of a Linear Polyelectrolyte on a Gold Electrode. PCCP 2003, 5, 4258-4264.

(216) Kleijn, J. M.; Barten, D.; Stuart, M. A. C. Adsorption of Charged Macromolecules at a Gold Electrode. Langmuir 2004, 20, 9703-9713.

(217) Bearinger, J. P.; Voros, J.; Hubbell, J. A.; Textor, M. Electrochemical Optical Waveguide Lightmode Spectroscopy (Ec-Owls): A Pilot Study Using Evanescent-Field Optical Sensing under Voltage Control to Monitor Polycationic Polymer Adsorption onto Indium Tin Oxide (Ito)-Coated Waveguide Chips. Biotechnol. Bioeng. 2003, 82, 465-473.

(218) Olsen, C.; Van Tassel, P. R. Polyelectrolyte Adsorption Kinetics under an Applied Electric Potential: Strongly Versus Weakly Charged Polymers. J. Colloid Interface Sci. 2009, 329, 222227.

(219) Mergel, O.; Kuhn, P. T.; Schneider, S.; Simon, U.; Plampera, F. A. Influence of Polymer Architecture on the Electrochemical Deposition of Polyelectrolytes. Electrochim. Acta 2017, 232, 98-105.

(220) Ngankam, A. P.; Van Tassel, P. R. In Situ Layer-by-Layer Film Formation Kinetics under an Applied Voltage Measured by Optical Waveguide Lightmode Spectroscopy. Langmuir 2005, $21,5865-5871$. 
(221) Dieguez, L.; Darwish, N.; Graf, N.; Voros, J.; Zambelli, T. Electrochemical Tuning of the Stability of PIl/DNA Multilayers. Soft Matter 2009, 5, 2415-2421.

(222) Van Tassel, P. R. Polyelectrolyte Adsorption and Layer-by-Layer Assembly:

Electrochemical Control. Curr. Opin. Colloid Interface Sci. 2012, 17, 106-113.

(223) Wang, S. W.; Chen, Z.; Umar, A.; Wang, Y.; Yin, P. G. Electric-Field Induced Layer-byLayer Assembly Technique with Single Component for Construction of Conjugated Polymer Films. Rsc Advances 2015, 5, 58499-58503.

(224) Sun, J. Q.; Gao, M. Y.; Zhu, M.; Feldmann, J.; Mohwald, H. Layer-by-Layer Depositions of Polyelectrolyte/Cdte Nanocrystal Films Controlled by Electric Fields. J. Mater. Chem. 2002, 12, 1775-1778.

(225) Ko, Y. H.; Kim, Y. H.; Park, J.; Nam, K. T.; Park, J. H.; Yoo, P. J. Electric-Field-Assisted Layer-by-Layer Assembly of Weakly Charged Polyelectrolyte Multilayers. Macromolecules 2011, 44, 2866-2872.

(226) Gao, M. Y.; Sun, J. Q.; Dulkeith, E.; Gaponik, N.; Lemmer, U.; Feldmann, J. Lateral Patterning of Cdte Nanocrystal Films by the Electric Field Directed Layer-by-Layer Assembly Method. Langmuir 2002, 18, 4098-4102.

(227) Omura, Y.; Kyung, K. H.; Shiratori, S.; Kim, S. H. Effects of Applied Voltage and Solution Ph in Fabricating Multilayers of Weakly Charged Polyelectrolytes and Nanoparticles. Ind. Eng. Chem. Res. 2014, 53, 11727-11733.

(228) Guzman, D.; Isaacs, M.; Osorio-Roman, I.; Garcia, M.; Astudino, J.; Ohlbaum, M. Photoelectrochemical Reduction of Carbon Dioxide on Quantum-Dot-Modified Electrodes by Electric Field Directed Layer-by-Layer Assembly Methodology. ACS Appl. Mater. Interfaces 2015, 7, 19865-19869.

(229) Shi, L. X.; Lu, Y. X.; Sun, J.; Zhang, J.; Sun, C. Q.; Liu, J. Q.; Shen, J. C. Site-Selective Lateral Multilayer Assembly of Bienzyme with Polyelectrolyte on Ito Electrode Based on Electric Field-Induced Directly Layer-by-Layer Deposition. Biomacromolecules 2003, 4, 11611167.

(230) Wu, F. H.; Hu, Z. C.; Wang, L. W.; Xu, J. J.; Xian, Y. Z.; Tian, Y.; Jin, L. T. Electric Field Directed Layer-by-Layer Assembly of Horseradish Peroxidase Nanotubes Via Anodic Aluminum Oxide Template. Electrochem. Commun. 2008, 10, 630-634. (231) Zamarreno, C. R.; Goicolechea, J.; Matias, I. R.; Arregui, F. J. Laterally Selective Adsorption of Ph Sensing Coatings Based on Neutral Red by Means of the Electric Field Directed Layer-by-Layer Self Assembly Method. Thin Solid Films 2009, 517, 3776-3780. (232) Zhang, P.; Qian, J. W.; Yang, Y.; An, Q. F.; Liu, X. Q.; Gui, Z. L. Polyelectrolyte Layerby-Layer Self-Assembly Enhanced by Electric Field and Their Multilayer Membranes for Separating Isopropanol-Water Mixtures. J. Membrane Sci. 2008, 320, 73-77.

(233) Zhang, P.; Qian, J. W.; An, Q. F.; Liu, X. Q.; Zhao, Q.; Jin, H. T. Surface Morphology and Pervaporation Performance of Electric Field Enhanced Multilayer Membranes. J. Membrane Sci. 2009, 328, 141-147.

(234) Ye, J. R.; Chen, L.; Zhang, Y.; Zhang, Q. C.; Shen, Q. Turning the Chitosan Surface from Hydrophilic to Hydrophobic by Layer-by-Layer Electro-Assembly. Rsc Advances 2014, 4, 58200-58203.

(235) Zhao, L. L.; Yuan, B. B.; Geng, Y. R.; Yu, C. N.; Kim, N. H.; Lee, J. H.; Li, P. Fabrication of Ultrahigh Hydrogen Barrier Polyethyleneimine/Graphene Oxide Films by Lbl Assembly FineTuned with Electric Field Application. Composites, Part A 2015, 78, 60-69. 
(236) Dochter, A.; Garnier, T.; Pardieu, E.; Chau, N. T. T.; Maerten, C.; Senger, B.; Schaaf, P.; Jierry, L.; Boulmedais, F. Film Self-Assembly of Oppositely Charged Macromolecules Triggered by Electrochemistry through a Morphogenic Approach. Langmuir 2015, 31, 1020810214.

(237) Liu, X. H.; Zhang, J. T.; Lynn, D. M. Polyelectrolyte Multilayers Fabricated from 'ChargeShifting' Anionic Polymers: A New Approach to Controlled Film Disruption and the Release of Cationic Agents from Surfaces. Soft Matter 2008, 4, 1688-1695.

(238) Garnier, T.; Dochter, A.; Chau, N. T. T.; Schaaf, P.; Jierry, L.; Boulmedais, F. Surface Confined Self-Assembly of Polyampholytes Generated from Charge-Shifting Polymers. Chem. Commun. 2015, 51, 14092-14095.

(239) Shi, X. W.; Tsao, C. Y.; Yang, X. H.; Liu, Y.; Dykstra, P.; Rubloff, G. W.; Ghodssi, R.; Bentley, W. E.; Payne, G. F. Electroaddressing of Cell Populations by Co-Deposition with Calcium Alginate Hydrogels. Adv. Funct. Mater. 2009, 19, 2074-2080.

(240) Cheng, Y.; Luo, X. L.; Betz, J.; Payne, G. F.; Bentley, W. E.; Rubloff, G. W. Mechanism of Anodic Electrodeposition of Calcium Alginate. Soft Matter 2011, 7, 5677-5684.

(241) Wan, W. F.; Dai, G. L.; Zhang, L. J.; Shen, Y. J. Paper-Based Electrodeposition Chip for 3d Alginate Hydrogel Formation. Micromachines 2015, 6, 1546-1559.

(242) Betz, J. F.; Cheng, Y.; Tsao, C. Y.; Zargar, A.; Wu, H. C.; Luo, X. L.; Payne, G. F.; Bentleyad, W. E.; Rubloff, G. W. Optically Clear Alginate Hydrogels for Spatially Controlled Cell Entrapment and Culture at Microfluidic Electrode Surfaces. Lab on a Chip 2013, 13, 18541858.

(243) Jin, Z. Y.; Guven, G.; Bocharova, V.; Halamek, J.; Tokarev, I.; Minko, S.; Melman, A.; Mandler, D.; Katz, E. Electrochemically Controlled Drug-Mimicking Protein Release from IronAlginate Thin-Films Associated with an Electrode. ACS Appl. Mater. Interfaces 2012, 4, 466475.

(244) Martin, E. J.; Sadman, K.; Shull, K. R. Anodic Electrodeposition of a Cationic Polyelectrolyte in the Presence of Multivalent Anions. Langmuir 2016, 32, 7747-7756.

(245) Cheng, Y.; Luo, X. L.; Tsao, C. Y.; Wu, H. C.; Betz, J.; Payne, G. F.; Bentley, W. E.; Rubloff, G. W. Biocompatible Multi-Address 3d Cell Assembly in Microfluidic Devices Using Spatially Programmable Gel Formation. Lab on a Chip 2011, 11, 2316-2318.

(246) Cheng, Y.; Tsao, C. Y.; Wu, H. C.; Luo, X. L.; Terrell, J. L.; Betz, J.; Payne, G. F.; Bentley, W. E.; Rubloff, G. W. Electroaddressing Functionalized Polysaccharides as Model Biofilms for Interrogating Cell Signaling. Adv. Funct. Mater. 2012, 22, 519-528.

(247) Ozawa, F.; Ino, K.; Arai, T.; Ramon-Azcon, J.; Takahashi, Y.; Shiku, H.; Matsue, T. Alginate Gel Microwell Arrays Using Electrodeposition for Three-Dimensional Cell Culture. Lab on a Chip 2013, 13, 3128-3135.

(248) Ozawa, F.; Ino, K.; Takahashi, Y.; Shiku, H.; Matsue, T. Electrodeposition of Alginate Gels for Construction of Vascular-Like Structures. J. Biosci. Bioeng. 2013, 115, 459-461. (249) Yang, X. H.; Kim, E.; Liu, Y.; Shi, X. W.; Rubloff, G. W.; Ghodssi, R.; Bentley, W. E.; Pancer, Z.; Payne, G. F. In-Film Bioprocessing and Immunoanalysis with Electroaddressable Stimuli-Responsive Polysaccharides. Adv. Funct. Mater. 2010, 20, 1645-1652. (250) Garcia-Torres, J.; Gispert, C.; Gomez, E.; Valles, E. Alginate Electrodeposition onto Three-Dimensional Porous Co-Ni Films as Drug Delivery Platforms. PCCP 2015, 17, 16301636. 
(251) Huang, S. H.; Chu, H. T.; Liou, Y. M.; Huang, K. S. Light-Addressable Electrodeposition of Magnetically-Guided Cells Encapsulated in Alginate Hydrogels for Three-Dimensional Cell Patterning. Micromachines 2014, 5, 1173-1187.

(252) Cosnier, S. Biomolecule Immobilization on Electrode Surfaces by Entrapment or Attachment to Electrochemically Polymerized Films. A Review. Biosens. Bioelectron. 1999, 14, 443-456.

(253) Ahuja, T.; Mir, I. A.; Kumar, D.; Rajesh. Biomolecular Immobilization on Conducting Polymers for Biosensing Applications. Biomaterials 2007, 28, 791-805.

(254) Schuhmann, W. Conducting Polymer Based Amperometric Enzyme Electrodes. Mikrochim. Acta 1995, 121, 1-29.

(255) Bartlett, P. N.; Cooper, J. M. A Review of the Immobilization of Enzymes in Electropolymerized Films. J. Electroanal. Chem. 1993, 362, 1-12. (256) Iwuoha, E. I.; de Villaverde, D. S.; Garcia, N. P.; Smyth, M. R.; Pingarron, J. M. Reactivities of Organic Phase Biosensors. 2. The Amperometric Behaviour of Horseradish Peroxidase Immobilised on a Platinum Electrode Modified with an Electrosynthetic Polyaniline Film. Biosens. Bioelectron. 1997, 12, 749-761.

(257) Rishpon, J.; Gottesfeld, S. Investigation of Polypyrrole Glucose-Oxidase Electrodes by Ellipsometric, Microgravimetric and Electrochemical Measurements. Biosens. Bioelectron. 1991, 6, 143-149.

(258) Fortier, G.; Brassard, E.; Belanger, D. Optimization of a Polypyrrole Glucose-Oxidase Biosensor. Biosens. Bioelectron. 1990, 5, 473-490.

(259) Wang, J. J.; Myung, N. V.; Yun, M. H.; Monbouquette, H. G. Glucose Oxidase Entrapped in Polypyrrole on High-Surface-Area Pt Electrodes: A Model Platform for Sensitive Electroenzymatic Biosensors. J. Electroanal. Chem. 2005, 575, 139-146.

(260) Zhang, Z. E.; Liu, H. Y.; Deng, J. Q. A Glucose Biosensor Based on Immobilization of Glucose Oxidase in Electropolymerized O-Aminophenol Film on Platinized Glassy Carbon Electrode. Anal. Chem. 1996, 68, 1632-1638.

(261) Malitesta, C.; Palmisano, F.; Torsi, L.; Zambonin, P. G. Glucose Fast-Response Amperometric Sensor Based on Glucose-Oxidase Immobilized in an Electropolymerized Poly(Ortho-Phenylenediamine) Film. Anal. Chem. 1990, 62, 2735-2740.

(262) Stojanovic, Z.; Erdossy, J.; Keltai, K.; Scheller, F. W.; Gyurcsanyi, R. E.

Electrosynthesized Molecularly Imprinted Polyscopoletin Nanofilms for Human Serum Albumin Detection. Anal. Chim. Acta 2017, 977, 1-9.

(263) Shumyantseva, V. V.; Bulko, T. V.; Sigolaeva, L. V.; Kuzikov, A. V.; Archakov, A. I.

Electrosynthesis and Binding Properties of Molecularly Imprinted Poly-O-Phenylenediamine for Selective Recognition and Direct Electrochemical Detection of Myoglobin. Biosens. Bioelectron. 2016, 86, 330-336.

(264) Peng, L.; Yarman, A.; Jetzschmann, K. J.; Jeoung, J. H.; Schad, D.; Dobbek, H.; Wollenberger, U.; Scheller, F. W. Molecularly Imprinted Electropolymer for a Hexameric Heme Protein with Direct Electron Transfer and Peroxide Electrocatalysis. Sensors 2016, 16, 272.

(265) Waltman, R. J.; Bargon, J. Electrically Conducting Polymers - a Review of the Electropolymerization Reaction, of the Effects of Chemical-Structure on Polymer Film Properties, and of Applications Towards Technology. Can. J. Chem. 1986, 64, 76-95. (266) Wojcik, K.; Iwan, A. Electrochemical Polymerization of Polymers for Photovoltaic Cell Applications. Polimery 2016, 61, 239-247. 
(267) Plamper, F. A. Polymerizations under Electrochemical Control. Colloid. Polym. Sci. 2014, 292, 777-783.

(268) Ates, M. A Review Study of (Bio)Sensor Systems Based on Conducting Polymers. Mater. Sci. Eng., C 2013, 33, 1853-1859.

(269) Erdossy, J.; Horvath, V.; Yarman, A.; Scheller, F. W.; Gyurcsanyi, R. E. Electrosynthesized Molecularly Imprinted Polymers for Protein Recognition. Trac-Trend Anal Chem 2016, 79, 179-190.

(270) Rydzek, G.; Thomann, J. S.; Ben Ameur, N.; Jierry, L.; Mesini, P.; Ponche, A.; Contal, C.; El Haitami, A. E.; Voegel, J. C.; Senger, B.; Schaaf, P.; Frisch, B.; Boulmedais, F. Polymer Multilayer Films Obtained by Electrochemically Catalyzed Click Chemistry. Langmuir 2010, 26, 2816-2824.

(271) Karon, K.; Lapkowski, M. Carbazole Electrochemistry: A Short Review. J. Solid State Electrochem. 2015, 19, 2601-2610.

(272) Li, M.; Ishihara, S.; Akada, M.; Liao, M. Y.; Sang, L. W.; Hill, J. P.; Krishnan, V.; Ma, Y. G.; Ariga, K. Electrochemical-Coupling Layer-by-Layer (Ecc-Lbl) Assembly. J. Am. Chem. Soc. 2011, 133, 7348-7351.

(273) Li, M.; Ishihara, S.; Ji, Q. M.; Ma, Y. G.; Hill, J. P.; Ariga, K. Electrochemical Coupling Layer-by-Layer (Ecc-Lbl) Assembly in Patterning Mode. Chem. Lett. 2012, 41, 383-385.

(274) Gao, Y. X.; Qi, J.; Zhang, J.; Kang, S. S.; Qiao, W. Q.; Li, M.; Sun, H. Z.; Zhang, J. P.; Ariga, K. Fabrication of Both the Photoactive Layer and the Electrode by Electrochemical Assembly: Towards a Fully Solution-Processable Device. Chem. Commun. 2014, 50, 1044810451.

(275) Rydzek, G.; Jierry, L.; Parat, A.; Thomann, J. S.; Voegel, J. C.; Senger, B.; Hemmerle, J.; Ponche, A.; Frisch, B.; Schaaf, P.; Boulmedais, F. Electrochemically Triggered Assembly of Films: A One-Pot Morphogen-Driven Buildup. Angew. Chem., Int. Ed. Engl. 2011, 50, 43744377.

(276) Potter, J. D. Morphogens, Morphostats, Microarchitecture and Malignancy. Nature Reviews Cancer 2007, 7, 464-474.

(277) Kolb, H. C.; Finn, M. G.; Sharpless, K. B. Click Chemistry: Diverse Chemical Function from a Few Good Reactions. Angew. Chem., Int. Ed. Engl. 2001, 40, 2004-2021.

(278) Rydzek, G.; Ji, Q. M.; Li, M.; Schaaf, P.; Hill, J. P.; Boulmedais, F.; Ariga, K. Electrochemical Nanoarchitectonics and Layer-by-Layer Assembly: From Basics to Future. Nano Today 2015, 10, 138-167.

(279) Rydzek, G.; Polavarapu, P.; Rios, C.; Tisserant, J. N.; Voegel, J. C.; Senger, B.; Lavalle, P.; Frisch, B.; Schaaf, P.; Boulmedais, F.; Jierry, L. Morphogen-Driven Self-Construction of Covalent Films Built from Polyelectrolytes and Homobifunctional Spacers: Buildup and $\mathrm{Ph}$ Response. Soft Matter 2012, 8, 10336-10343.

(280) Hu, L. J.; Zhao, P. K.; Deng, H. B.; Xiao, L.; Qin, C. Q.; Du, Y. M.; Shi, X. W. Electrical Signal Guided Click Coating of Chitosan Hydrogel on Conductive Surface. Rsc Advances 2014, 4, 13477-13480.

(281) Rydzek, G.; Parat, A.; Polavarapu, P.; Baehr, C.; Voegel, J. C.; Hemmerle, J.; Senger, B.; Frisch, B.; Schaaf, P.; Jierry, L.; Boulmedais, F. One-Pot Morphogen Driven Self-Constructing Films Based on Non-Covalent Host-Guest Interactions. Soft Matter 2012, 8, 446-453.

(282) Rydzek, G.; Garnier, T.; Schaaf, P.; Voegel, J. C.; Senger, B.; Frisch, B.; Haikel, Y.; Petit, C.; Schlatter, G.; Jierry, L.; Boulmedais, F. Self-Construction of Supramolecular Polyrotaxane Films by an Electrotriggered Morphogen-Driven Process. Langmuir 2013, 29, 10776-10784. 
(283) Rydzek, G.; Toulemon, D.; Garofalo, A.; Leuvrey, C.; Dayen, J. F.; Felder-Flesch, D.; Schaaf, P.; Jierry, L.; Begin-Colin, S.; Pichon, B. P.; Boulmedais, F. Selective Nanotrench Filling by One-Pot Electroclick Self-Constructed Nanoparticle Films. Small 2015, 11, 46384642.

(284) Rydzek, G.; Terentyeva, T. G.; Pakdel, A.; Golberg, D.; Hill, J. P.; Ariga, K. Simultaneous Electropolymerization and Electro-Click Functionalization for Highly Versatile Surface Platforms. Acs Nano 2014, 8, 5240-5248.

(285) Gray, K. M.; Liba, B. D.; Wang, Y. F.; Cheng, Y.; Rubloff, G. W.; Bentley, W. E.; Montembault, A.; Royaud, I.; David, L.; Payne, G. F. Electrodeposition of a Biopolymeric Hydrogel: Potential for One-Step Protein Electroaddressing. Biomacromolecules 2012, 13, 11811189.

(286) Liba, B. D.; Kim, E.; Martin, A. N.; Liu, Y.; Bentley, W. E.; Payne, G. F. Biofabricated Film with Enzymatic and Redox-Capacitor Functionalities to Harvest and Store Electrons. Biofabrication 2013, 5, 015008.

(287) Maerten, C.; Garnier, T.; Lupattelli, P.; Chau, N. T. T.; Schaaf, P.; Jierry, L.; Boulmedais, F. Morphogen Electrochemically Triggered Self-Construction of Polymeric Films Based on Mussel-Inspired Chemistry. Langmuir 2015, 31, 13385-13393.

(288) Waite, J. H.; Tanzer, M. L. Polyphenolic Substance of Mytilus-Edulis - Novel Adhesive Containing L-Dopa and Hydroxyproline. Science 1981, 212, 1038-1040.

(289) Waite, J. H. Nature's Underwater Adhesive Specialist. Int. J. Adhesion and Adhesives 1987, 7, 9-14.

(290) Li, M.; Zhang, J.; Nie, H. J.; Liao, M. Y.; Sang, L. W.; Qiao, W. Q.; Wang, Z. Y.; Ma, Y. G.; Zhong, Y. W.; Ariga, K. In Situ Switching Layer-by-Layer Assembly: One-Pot Rapid Layer Assembly Via Alternation of Reductive and Oxidative Electropolymerization. Chem. Commun. 2013, 49, 6879-6881.

(291) Ariga, K.; Malgras, V.; Ji, Q. M.; Zakaria, M. B.; Yamauchi, Y. Coordination Nanoarchitectonics at Interfaces between Supramolecular and Materials Chemistry. Coord. Chem. Rev. 2016, 320, 139-152.

(292) Friese, V. A.; Kurth, D. G. From Coordination Complexes to Coordination Polymers through Self-Assembly. Curr. Opin. Colloid Interface Sci. 2009, 14, 81-93.

(293) Gangu, K. K.; Maddila, S.; Mukkamala, S. B.; Jonnalagadda, S. B. A Review on Contemporary Metal-Organic Framework Materials. Inorg. Chim. Acta 2016, 446, 61-74. 
TOC

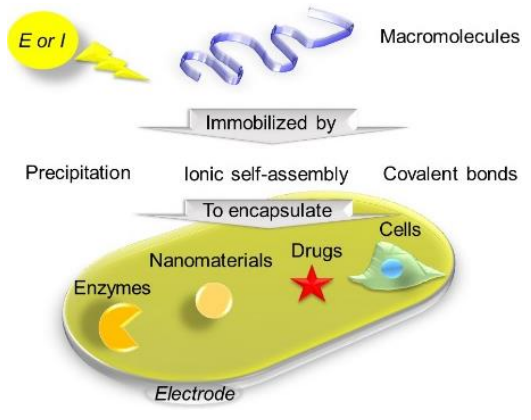

